\title{
The Nonlinear Patterns of North American Winter Temperature and Precipitation Associated with ENSO
}

\author{
Aiming Wu ANd William W. HsieH \\ Department of Earth and Ocean Sciences, University of British Columbia, Vancouver, British Columbia, Canada \\ AMIR SHABBAR \\ Climate Research Branch, Meteorological Service of Canada, Downsview, Ontario, Canada
}

(Manuscript received 4 March 2004, in final form 15 September 2004)

\begin{abstract}
Nonlinear projections of the tropical Pacific sea surface temperature anomalies (SSTAs) onto North American winter (November-March) surface air temperature (SAT) and precipitation anomalies have been performed using neural networks. During El Niño, the linear SAT response has positive anomalies centered over Alaska and western Canada opposing weaker negative anomalies centered over the southeastern United States. In contrast, the nonlinear SAT response, which is excited during both strong El Niño and strong La Niña, has negative anomalies centered over Alaska and northwestern Canada and positive anomalies over much of the United States and southern Canada.

For precipitation, the linear response during El Niño has a positive anomaly area stretching from the east coast to the southwest coast of the United States and another positive area in northern Canada, in opposition to the negative anomaly area over much of southern Canada and northern United States, and another negative area over Alaska. In contrast, the nonlinear precipitation response, which is excited during both strong El Niño and strong La Niña, displays positive anomalies over much of the United States and southern Canada, with the main center on the west coast at around $45^{\circ} \mathrm{N}$ and a weak center along the southeast coast, and negative anomalies over northwestern Canada and Alaska.

The nonlinear response accounts for about one-fourth and one-third as much variance as the linear response of the SAT and precipitation, respectively. A polynomial fit further verifies the nonlinear response of both the SAT and precipitation to be mainly a quadratic response to ENSO. Both the linear and nonlinear response patterns of the SAT and precipitation are basically consistent with the circulation anomalies (the 500-mb geopotential height anomalies), detected separately by nonlinear projection. A cross-validation test shows that including the nonlinear (quadratic) response can potentially contribute to additional forecast skill over North America.
\end{abstract}

\section{Introduction}

The impact of the El Niño-Southern Oscillation (ENSO) phenomenon on global climate, especially the North American climate variability, has received wide attention since the early 1980s (Trenberth et al. 1998). The extratropical atmospheric response to El Niño in northern winter is manifested by the Pacific-North American (PNA) teleconnection pattern, which can be found simply by linear regression or correlation analy-

Corresponding author address: Dr. Aiming Wu, Dept. of Earth and Ocean Sciences, University of British Columbia, Vancouver, BC, V6T 1Z4, Canada.

E-mail: awu@eos.ubc.ca sis (Wallace and Gutzler 1981; Horel and Wallace 1981), and is rather well explained by the linear wave propagation theory (Hoskins and Karoly 1981).

Though the PNA pattern accounts for a considerable part of the variance of interannual climate fluctuations over the North Pacific and North America and is regarded as a major source of skill for seasonal forecasts (e.g., Zwiers 1987; Barnston 1994; Shabbar and Barnston 1996; Derome et al. 2001), recent evidence from observational studies and numerical models showed the North American climate to have asymmetric response patterns during the opposite phases of ENSO, suggesting that the North American climate responds to ENSO in a nonlinear fashion. For example, compositing monthly fields of the U.S. surface air temperature 
(SAT), precipitation, and 700-mb height based on the sea surface temperature anomalies (SSTAs) in the central equatorial Pacific, Livezey et al. (1997) found that the fields associated with warm and cold episodes have different spatial structures. The asymmetric patterns of Canadian SAT and precipitation associated with ENSO were investigated by Shabbar and Khandekar (1996) and Shabbar et al. (1997). Composited precipitation patterns over central and eastern North America associated with the SSTA in different regions of the tropical Pacific were studied by Montroy et al. (1998). The dynamic foundation for nonlinear atmospheric response to ENSO was discussed by Hoerling et al. (1997), where observed and modeled 500-mb northern Pacific circulation anomalies associated with warm episodes are shifted by about $35^{\circ}$ eastward relative to their counterparts during cold episodes.

Suppose $x$ denotes the ENSO sea surface temperature (SST) index and $\mathbf{y}$ denotes the extratropical atmospheric response to ENSO. To properly understand the nonlinear extratropical atmospheric response to ENSO, one would need to derive the nonlinear response function $\mathbf{y}=\mathbf{f}(x)$. Unfortunately, this nonlinear problem is oversimplified by using classical linear statistical tools.

Composite analysis is a common way to present the nonlinear atmospheric response patterns associated with tropical Pacific warm (El Niño) and cold (La Niña) episodes by averaging the data over the years when warm episodes occurred and averaging over the years when cold episodes occurred. While the patterns during warm and cold episodes are not restricted to be antisymmetrical, composite analysis does not yield a nonlinear response function. "One-sided regression" calculates a linear regression between the SST index and the response variable when the SST index is positive and another linear regression when the SST index is negative (Hoerling et al. 2001), thereby describing the nonlinear atmospheric response with a very restrictive nonlinear function. The advent of neural network (NN) methods has made the general nonlinear problem tractable and has led to the nonlinear generalization of regression, classification, principal component analysis (PCA), singular spectrum analysis, and canonical correlation analysis (CCA; see reviews by Hsieh and Tang 1998; Hsieh 2004).

The linear response to ENSO can be easily obtained by a linear projection, that is, a linear regression of the atmospheric variables on the ENSO SST index. The nonlinear projection can be achieved via a NN approach (henceforth a NN projection). The nonlinear projections of the tropical Pacific SSTA to the Northern Hemisphere winter 500-mb geopotential height
$\left(Z_{500}\right)$ anomalies and to the sea level pressure anomalies have been performed by Wu and Hsieh (2004a) and Wu and Hsieh (2004b), respectively. Compared to the nonlinear canonical correlation analysis (Hsieh 2001), the nonlinear projection has a much simpler NN structure with far fewer model parameters; hence it is easier to obtain robust results from noisy data.

In this work, the NN projection method will be further used to investigate the nonlinear association between ENSO and North American winter SAT and precipitation. The data and the method are briefly introduced in section 2 . The nonlinear SAT anomaly patterns associated with El Niño and La Niña detected by the NN projection, and separately by a polynomial fit, are presented in section 3. Similar analysis for the precipitation is presented in section 4 . Section 5 relates the SAT and precipitation response to the atmospheric circulation $\left(Z_{500}\right)$ response to ENSO. Section 6 gives a summary and discussion. The appendix examines the potential increase in forecast skills by including the nonlinearity.

\section{Data and methodology}

a. Data

The monthly SST data on a $2^{\circ} \times 2^{\circ}$ grid for the period 1950-2002 came from the Extended Reconstructed Sea Surface Temperatures, version 2 (ERSST2) dataset (Smith and Reynolds 2004). The SST anomalies were calculated by subtracting the monthly climatology (based on the whole period) from the monthly mean SST. The ENSO SST index is defined as the standardized first principal component (PC) of the winter (November-March) SSTA over the tropical Pacific $\left(22^{\circ} \mathrm{S}-22^{\circ} \mathrm{N}, 122^{\circ} \mathrm{E}-72^{\circ} \mathrm{W}\right)$, which is correlated with both the Niño-3 and Niño-3.4 indices at 0.96. A PC-based ENSO SST index was also used by Hoerling et al. (2001) but with the domain expanded to $30^{\circ} \mathrm{S}-30^{\circ} \mathrm{N}$.

The monthly land SAT and precipitation data came from the Climate Research Unit (CRU) at the University of East Anglia, United Kingdom (Mitchell et al. 2003, manuscript submitted to J. Climate; or see http:// www.cru.uea.ac.uk/cru/data/hrg.htm). The CRU provided data on a $0.5^{\circ} \times 0.5^{\circ}$ grid for the period 19012002. In this study, only the data after 1950 were used. Similarly, the SAT and precipitation anomalies were calculated by subtracting the monthly climatology with only the winter (November-March) data over North America used. A notable feature of the precipitation data is that the precipitation anomalies have much larger magnitudes near the coast than inland, which can be seen from the distribution of standard deviation of 


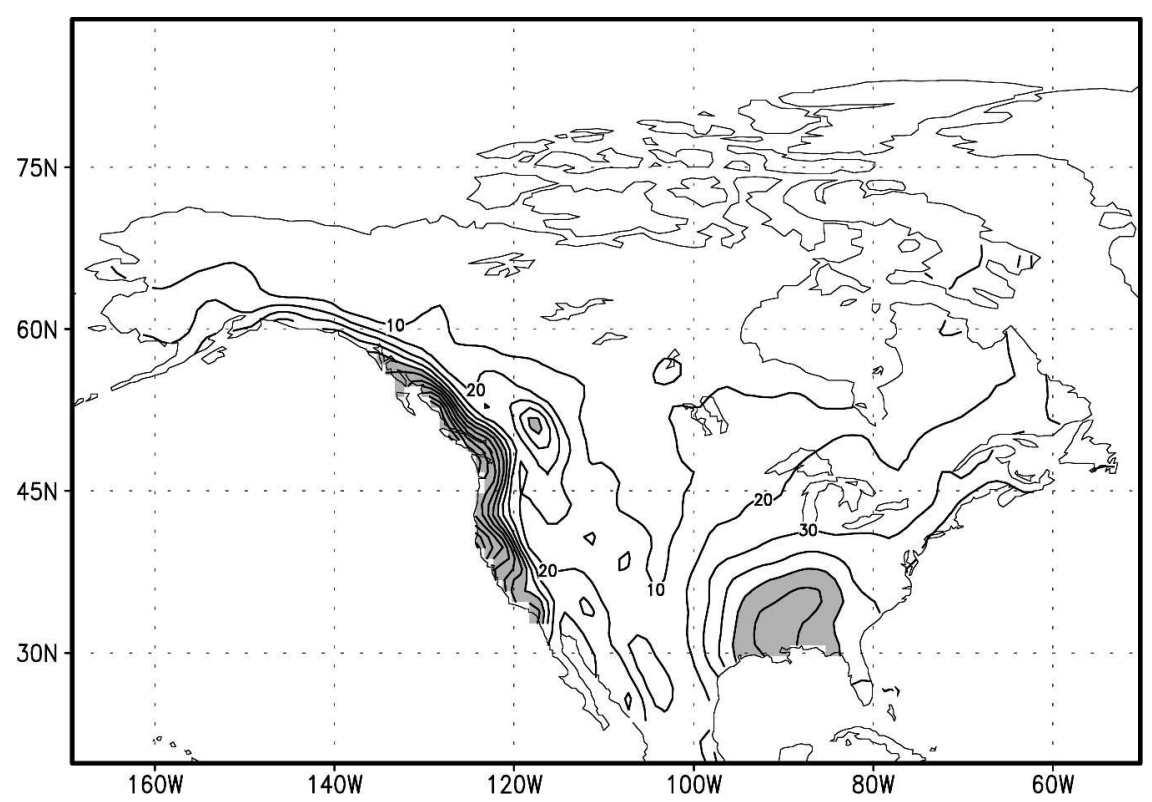

FIG. 1. The standard deviation of North American winter precipitation. The contour interval is $10 \mathrm{~mm}$; shaded areas indicate values larger than $50 \mathrm{~mm}$.

the precipitation (Fig. 1). PCA was used to compress the data, with the 8 leading SAT PCs and the 12 leading precipitation PCs (accounting for $89.4 \%$ and $69.6 \%$ of the total variance of the SAT and precipitation anomalies, respectively) retained.

The spatial patterns of the three leading PCA modes [also called empirical orthogonal functions (EOFs)] for the SAT and precipitation anomalies are shown in Fig.

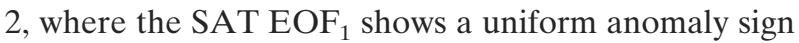
over the whole domain except the southeastern United States (Fig. 2a), and $\mathrm{EOF}_{2}$ reveals SAT anomalies over the United States and southern Canada in opposition to the anomalies over Alaska and northern Canada (Fig. $2 \mathrm{~b}$ ), whereas the SAT EOF 3 shows the northeast half of the continent to have anomalies opposite in sign to the rest (Fig. 2c). The precipitation $\mathrm{EOF}_{1}$ (Fig. 2d) shows anomalies in northwestern Canada and Mexico opposing anomalies over other areas of the continent; $\mathrm{EOF}_{2}$ displays anomalies over the west coast [from British Columbia (BC) to northern California] stretching eastward, opposing the anomalies in Alaska, northern Canada, and in the southern United States (Fig. 2e), while $\mathrm{EOF}_{3}$ shows almost a uniform sign over the domain except the west coast of the United States with strong anomalies over the southeastern United States (Fig. 2f).

\section{b. The nonlinear projection}

A schematic diagram of the multilayer perceptron NN model with one hidden layer is shown in Fig. 3. The
NN has a single input, the SST index $(x)$, which is nonlinearly mapped to $m$ intermediate variables, called hidden neurons $\left(h_{i}, i=1, \cdots, m\right)$, which are then linearly mapped to $l$ output variables $\left(y_{j}, j=1, \cdots, l\right)$, that is,

$$
\begin{aligned}
& h_{i}=\tanh \left(w_{i} x+b_{i}\right), \\
& y_{j}=\sum_{i=1}^{m} \tilde{w}_{j i} h_{i}+\tilde{b}_{j},
\end{aligned}
$$

where $w_{i}$ and $\tilde{w}_{j i}$ form an $m$-element weight vector $(\mathbf{w})$ and an $l \times m$ weight matrix $(\mathbf{W})$, respectively, while $b_{i}$ and $\tilde{b}_{j}$ form bias vectors (b and $\tilde{\mathbf{b}}$ ) of length $m$ and $l$, respectively. With enough hidden neurons, the NN model is capable of modeling any nonlinear continuous function to arbitrary accuracy. Starting from random initial values, the model parameters (in $\mathbf{w}, \mathbf{W}, \mathbf{b}$, and $\tilde{\mathbf{b}}$ ) are optimized so that the mean square error (MSE) between the model outputs (y) and the leading PCs $\left(\mathbf{y}^{\text {obs }}\right)$ of the SAT (or precipitation) anomalies is minimized. There is no time lag between $x$ and $y^{\text {obs }}$. To avoid local minima during optimization, the NN model was trained 30 times with random initial conditions. Among the runs, the solution with the smallest MSE was chosen and the other 29 rejected.

To reduce the possible sampling dependence of a single NN solution, we repeated the above calculation 400 times with a bootstrap approach (Efron and Tibshirani 1993). A bootstrap sample was obtained by randomly selecting (with replacement) one winter's data 
(a) SAT EOF1 $36.5 \%$

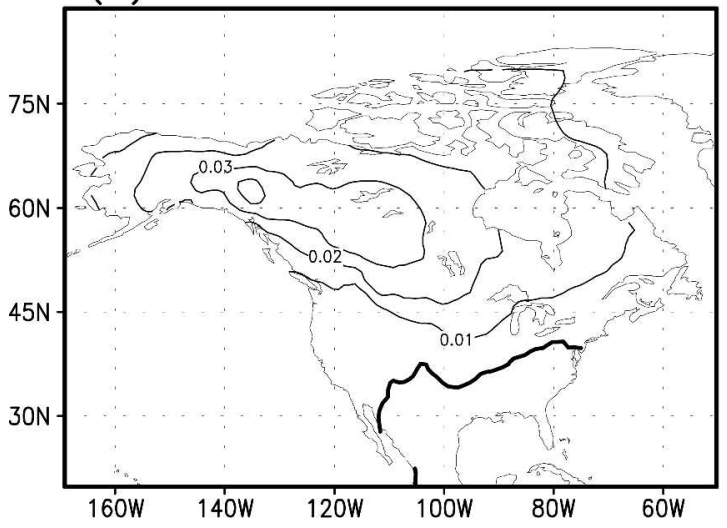

(b) SAT EOF2 $19.5 \%$

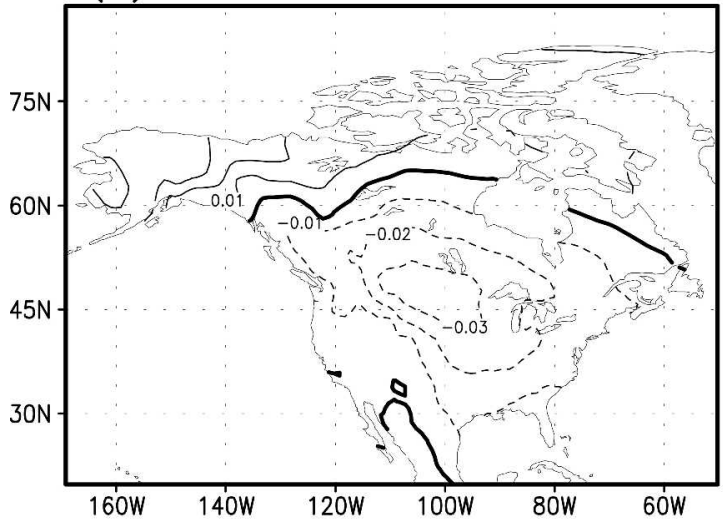

(c) SAT EOF3 $14.7 \%$

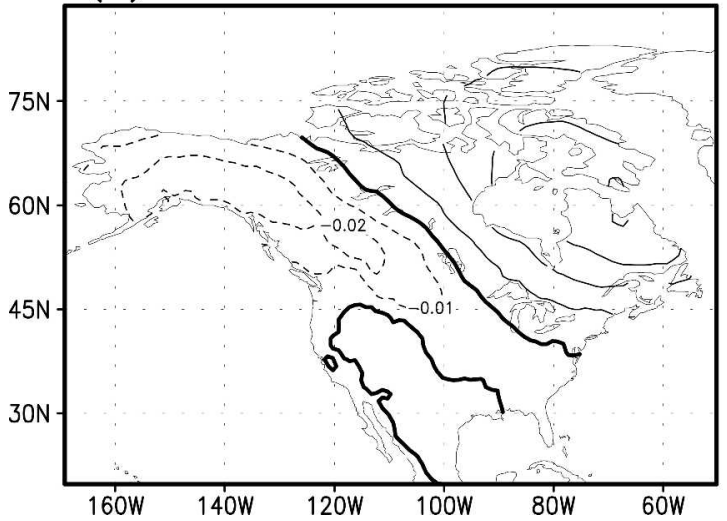

(d) PRCP EOF1 $17.3 \%$

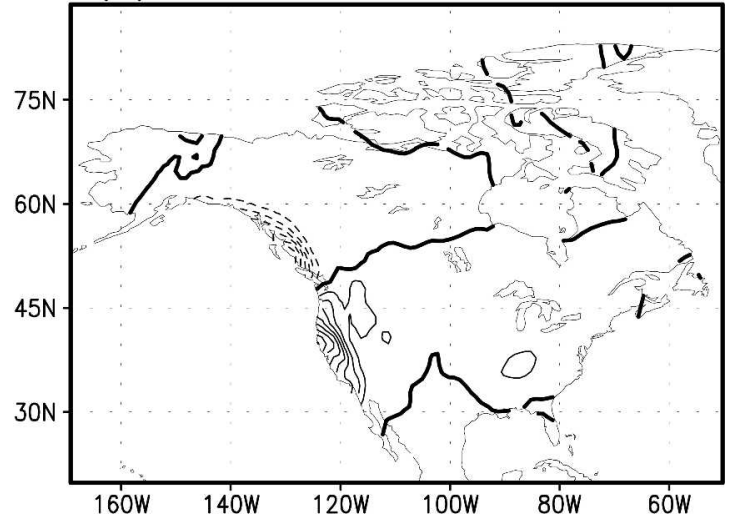

(e) PRCP EOF2 $14.3 \%$

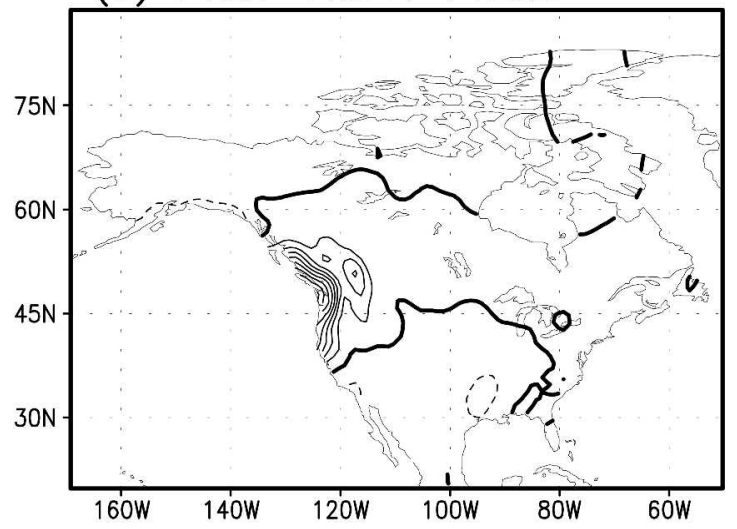

(f) PRCP EOF3 $11.1 \%$

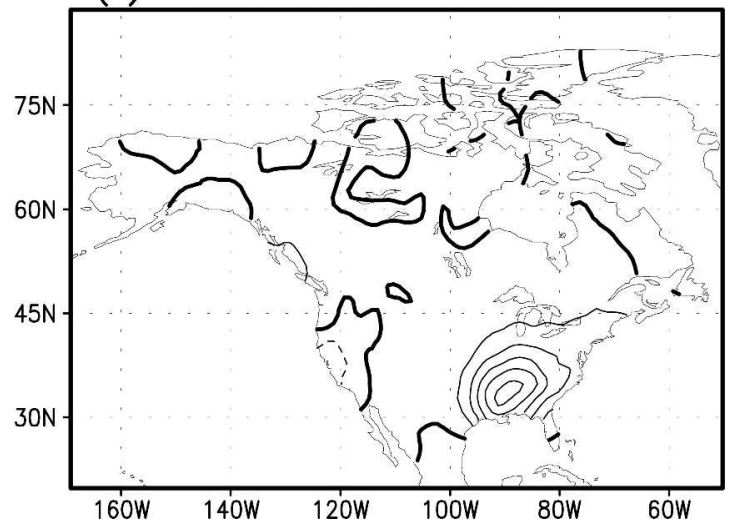

FIG. 2. (a)-(c) The three leading EOFs of the North American winter SAT anomalies and (d)-(f) the EOFs of the precipitation anomalies; solid curves: positive contours, dashed curves: negative contours, and thick curves: zero contours. The contour interval is 0.01 for the SAT and 0.02 for the precipitation, and the EOFs have been normalized to unit norm. The percentage variance explained by each EOF is given in the figure titles.

record 53 times from the original record of 53 winters. The ensemble mean of the resulting $400 \mathrm{NN}$ models was used as the final $\mathrm{NN}$ model, which was found to be insensitive to the number of hidden neurons that was varied from two to five in a sensitivity test. Results from using three hidden neurons are presented here.

If the nonlinear mapping function, tanh in Eq. (1), is replaced by a linear function, the $\mathrm{NN}$ model is essentially reduced to linear regression. 


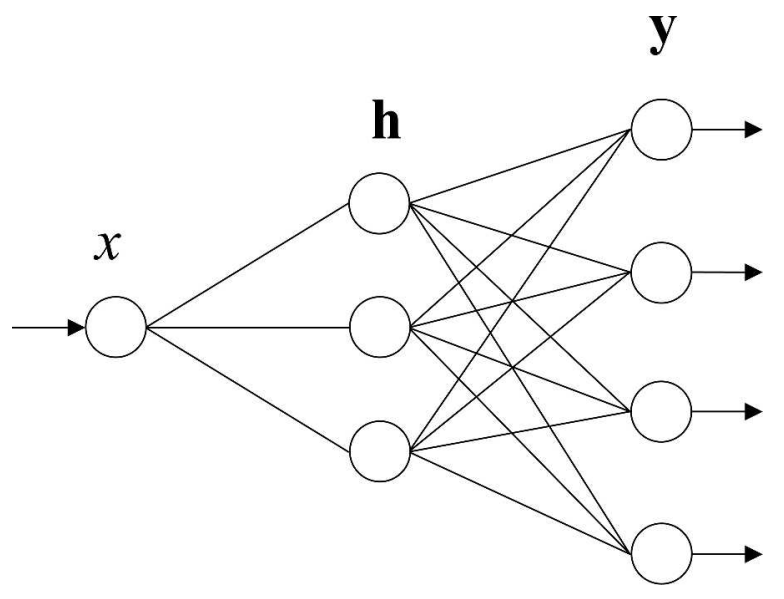

FIG. 3. Schematic diagram of the feed-forward neural network model used to perform the nonlinear projection. The $\mathrm{NN}$ has a single input $x$, which is nonlinearly mapped to intermediate variables (called hidden neurons) $\mathbf{h}$, which are then linearly mapped to the output variables $\mathbf{y}$. The model parameters are optimized by minimizing the mean square error given by the cost function $J=$ $\left\langle\left\|\mathbf{y}-\mathbf{y}^{\mathrm{obs}}\right\|^{2}\right\rangle$, where $\mathbf{y}^{\mathrm{obs}}$ is the observed data, and $\langle\cdots\rangle$ denotes a sample or time mean. In this study, $x$ is the ENSO SST index, and $\mathbf{y}^{\text {obs }}$ the 8 leading PCs of the North American SAT or the 12 leading PCs of the precipitation anomalies, with three hidden neurons used in both cases.

\section{The nonlinear patterns of SAT associated with ENSO}

\section{a. The NN projection results}

In the NN model, since the output PCs are all derived from a single time series (the ENSO index), the atmospheric response extracted by the nonlinear projection can be presented by a curve in the eight-dimensional (8D) phase space of the SAT PCs, while the linear projection extracts a straight line in the same $8 \mathrm{D}$ space. This curve is parabola-like (Fig. 4) when projected onto the $\mathrm{PC}_{1}-\mathrm{PC}_{2}$ plane and the $\mathrm{PC}_{2}-\mathrm{PC}_{3}$ plane, indicating that the SAT response to the ENSO SST index is a nonlinear combination of some of its leading PCA modes. For a specific value of the SST index, the NN solution gives the eight SAT PCs (the output of the NN model; Fig. 3), which can be combined with the corresponding EOFs, yielding the SAT spatial anomalies associated with the given SST. As the SST index varies slowly from its minimum value to its maximum value, the SAT response moves smoothly along the $3 \mathrm{D}$ curve in Fig. 4 from the end labeled "c" to the other end labeled "w" (corresponding to the extreme cold and warm episodes, respectively), with both the spatial pattern and amplitude changing; in contrast, the linear response is restricted along the straight line in Fig. 4, manifesting a variable amplitude but a fixed spatial pattern.
When the SST index takes on its minimum value (i.e., strong La Niña), significant negative SAT anomalies appear over Alaska and northwestern Canada and positive anomalies over the southeastern United States (Fig. 5a). When the SST index takes on its maximum value (i.e., strong El Niño), the SAT anomaly center is shifted southeastward to the Great Plains (west of the Great Lakes) with the sign reversed (to become positive), and with weak negative anomalies appearing over northeastern Canada and over the southern United States-Mexico (Fig. 5d). The SAT patterns shown in Figs. 5a and 5d are well consistent with the composite results (Hoerling et al. 1997) and the one-sided regression results (Hoerling et al. 2001). The asymmetry between the SAT anomaly pattern in Fig. 5a and that in Fig. 5d suggests a considerably nonlinear association between ENSO and the North American winter SAT.

The displacement between the negative SAT anomaly center in Fig. 5a and the positive SAT anomaly center in Fig. 5d is understandable. In Fig. 4, at the $\mathbf{c}$ end, negative $\mathrm{PC}_{1}$ concurs with negative $\mathrm{PC}_{2}$ and positive $\mathrm{PC}_{3}$, which when combined with the corresponding EOFs (Fig. 2) is favorable for the formation of the SAT anomaly pattern shown in Fig. 5a; whereas at the $\mathbf{w}$ end, positive $\mathrm{PC}_{1}$ concurs with negative $\mathrm{PC}_{2}$ and negative $\mathrm{PC}_{3}$, which is favorable for the $\mathrm{SAT}$ anomaly pattern in Fig. 5d.

Figures $5 \mathrm{~b}$ and $5 \mathrm{e}$ show, respectively, the SAT anomalies when the SST index is at half its minimum value and at half its maximum value. The SAT anomalies decrease in magnitude, but the antisymmetry between Figs. 5b and 5e is much enhanced (relative to Figs. 5a and 5d), suggesting that at these half-minimum and half-maximum SST values the extratropical SAT response is largely linear.

To illustrate the nonlinear response in the SAT anomalies to the tropical SSTA, we plotted in Fig. 5c the difference between the SAT anomalies in Fig. 5a and twice the anomalies in Fig. 5b and similarly in Fig. 5f, the difference between the anomalies in Fig. $5 \mathrm{~d}$ and twice the anomalies in Fig. 5e. Interestingly, despite the strong asymmetry between Figs. $5 \mathrm{a}$ and $5 \mathrm{~d}$, and the considerable antisymmetry between Figs. $5 \mathrm{~b}$ and $5 \mathrm{e}$, the SAT anomalies in Figs. 5c and $5 \mathrm{f}$ are in good agreement, indicating that regardless of the sign of the SST index the nonlinear response has positive SAT anomalies appearing over much of the United States and south-central Canada and negative SAT anomalies over Alaska and northern Canada. It is this nonlinear response that brings forth the asymmetric SAT anomalies during the extreme cold and warm episodes (Figs. $5 a$ and $5 d$ ).

To ensure that the finding above is not the result of 


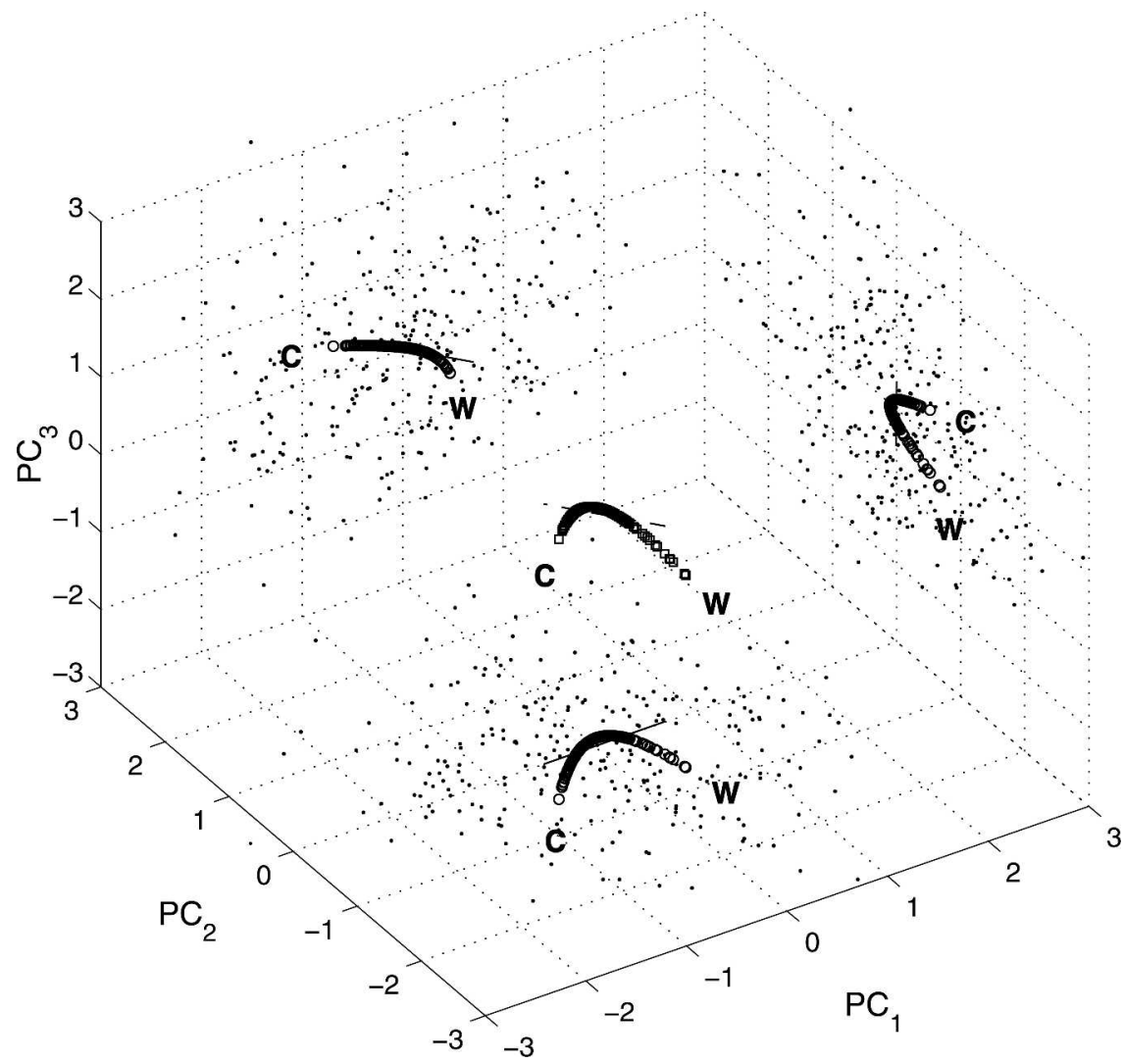

FIG. 4. The SAT response to the ENSO SST index extracted by the NN projection shown as a thick curve of overlapping squares in the $\mathrm{PC}_{1}-\mathrm{PC}_{2}-\mathrm{PC}_{3} 3 \mathrm{D}$ space. The linear response is shown by a thin straight dashed line. The SAT signal is also projected onto the $\mathrm{PC}_{1}-\mathrm{PC}_{2}, \mathrm{PC}_{2}-$ $\mathrm{PC}_{3}$, and $\mathrm{PC}_{1}-\mathrm{PC}_{3}$ planes, where the nonlinear projection is presented by the curves of overlapping circles, the linear projection by thin solid lines, and the projected data points by the scattered dots. The labels "c" and "w" denote the extreme cold and warm states, respectively.

fitting to one or two extreme cases, we repeated our bootstrap calculations but deleting the two winters with the strongest ENSO warm episodes (1982/83 and 1997/ 98), and the two winters with the strongest cold episodes (1973/74 and 1975/76) from the data record. Even without the extreme ENSO episodes, the resulting NN projection yielded basically the same spatial patterns as in Fig. 5 (with somewhat smaller magnitude anomalies), thereby confirming that the nonlinear response found by our $\mathrm{NN}$ projection was a robust result.

\section{b. The linear and nonlinear components of the $S A T$ response}

The NN-projected SAT anomalies can be decomposed into a linear component, that is, the linear projection (the straight line in Fig. 4) and a nonlinear component - the residual after the linear projection has been subtracted from the NN projection, that is, the eight PCs from the NN projection minus the eight PCs from the linear projection. The resulting eight PCs for the linear and nonlinear components can then be combined with the corresponding EOFs to yield the linear and nonlinear responses of SAT to ENSO. The linear and nonlinear components account for $80.4 \%$ and $19.6 \%$, respectively, of the variance in SAT anomaly data derived from the NN projection; in other words, the nonlinear response has almost one-fourth the variance of the linear response.

PCA is then used to separately analyze the linear and nonlinear response fields of the SAT anomalies during the period from January 1950 to December 2002 (with only winter months), where over $99 \%$ of the variance for either data field can be explained by its first PCA mode (the high percentage of variance explained is not surprising since the SAT anomaly field was generated originally by nonlinearly projecting from a single SST index time series). When the $\mathrm{PC}_{1}$ of the linear response (the solid line in Fig. 6a) takes on a positive value, the $\mathrm{EOF}_{1}$ of the linear response (Fig. 6b) shows positive 
(a) $\min$

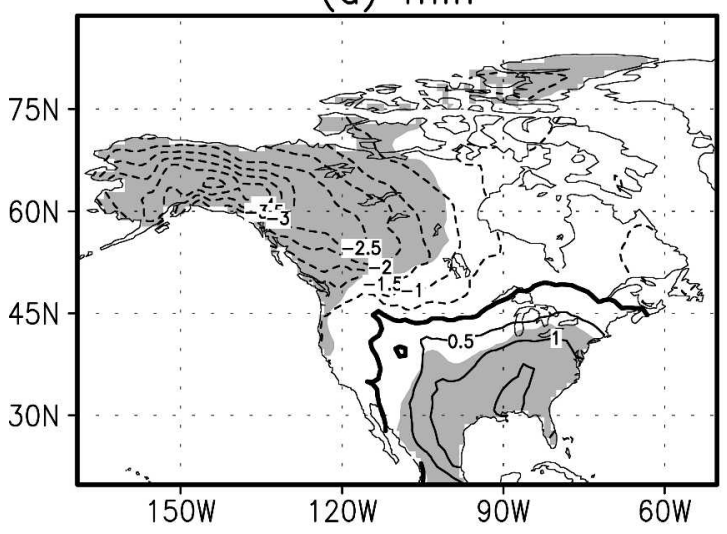

(b) $\min / 2$

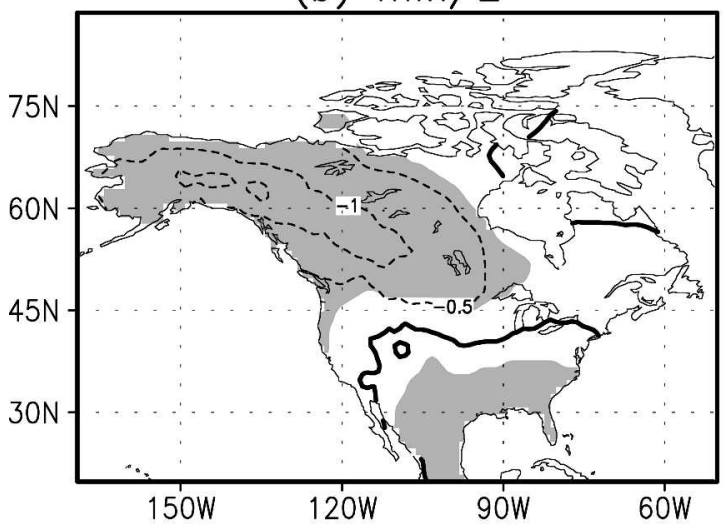

(c) $a-2 * b$

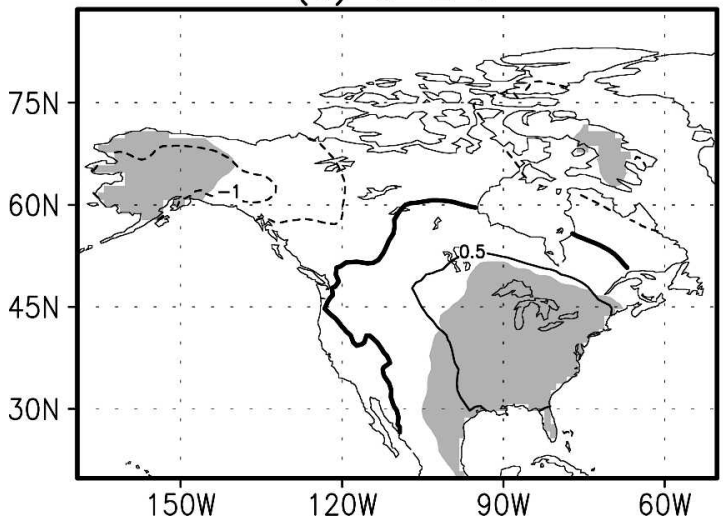

(d) $\max$

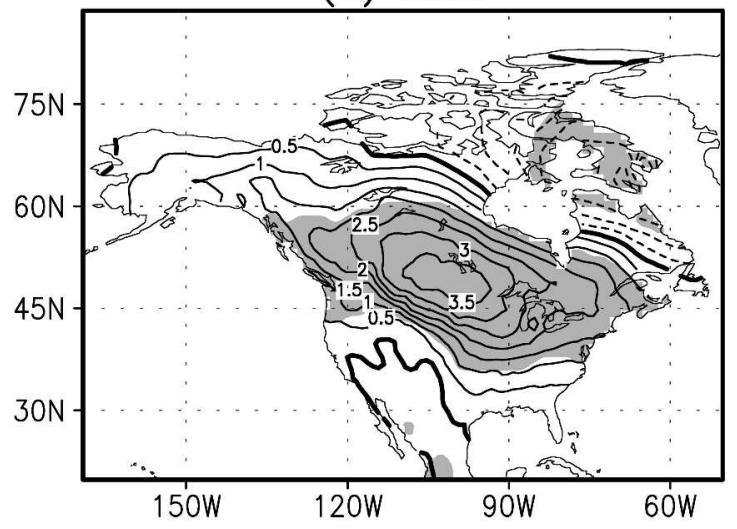

(e) $\max / 2$

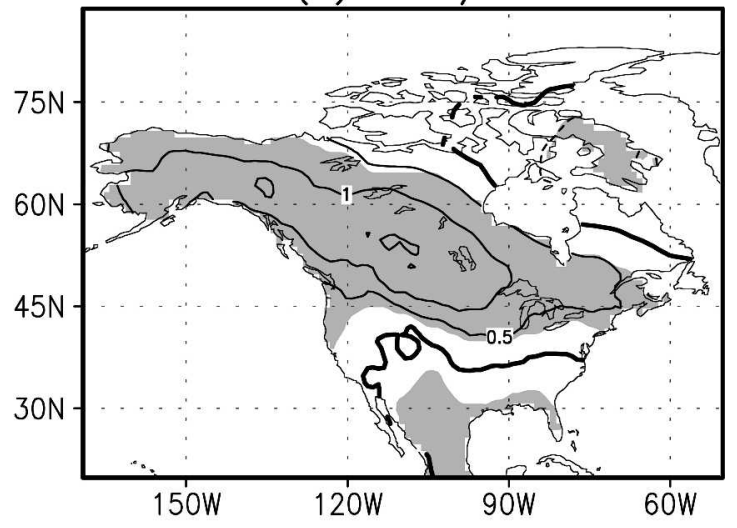

(f) $d-2 * e$

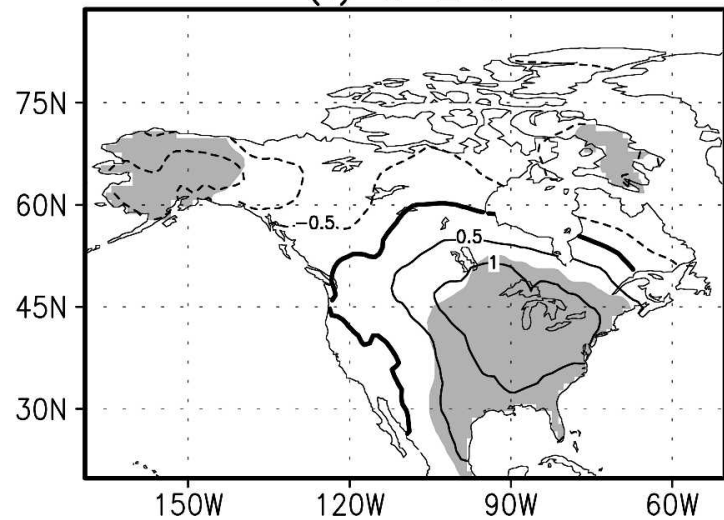

FIG. 5. The SAT anomalies associated with the (a) minimum SST index and (d) maximum SST index, and with (b) one-half of the minimum SST and (e) one-half of the maximum SST. (c) The SAT anomalies in (a) minus twice the anomalies in (b), and (f) the anomalies in (d) minus twice the anomalies in (e). If the SAT response to the SST index is strictly linear, then (c) and (f) will show zero everywhere. Contour interval is $0.5^{\circ} \mathrm{C}$, and the gray areas indicate statistical significance at the $5 \%$ level, based on the distribution of the results from the 400 bootstrap samples.

SAT anomalies appearing over western Canada and Alaska and negative anomalies over northeastern Canada and the southern United States, which can be interpreted by the classical PNA teleconnection pat- tern. The $\mathrm{EOF}_{1}$ of the nonlinear component (Fig. 6c) shows positive SAT anomalies over the United States and south-central Canada (with the center located in the Great Lakes region) and negative anomalies over 
(a)

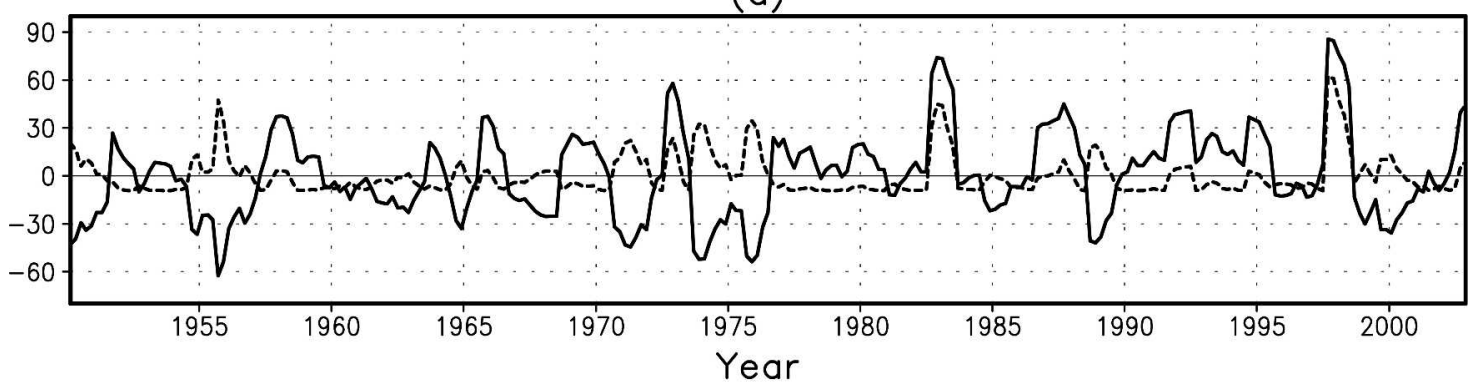

(b) Lin

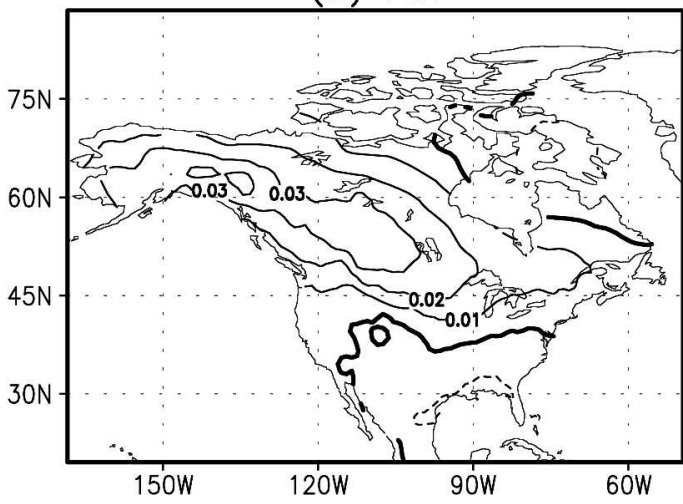

(c) $\mathrm{NL}$

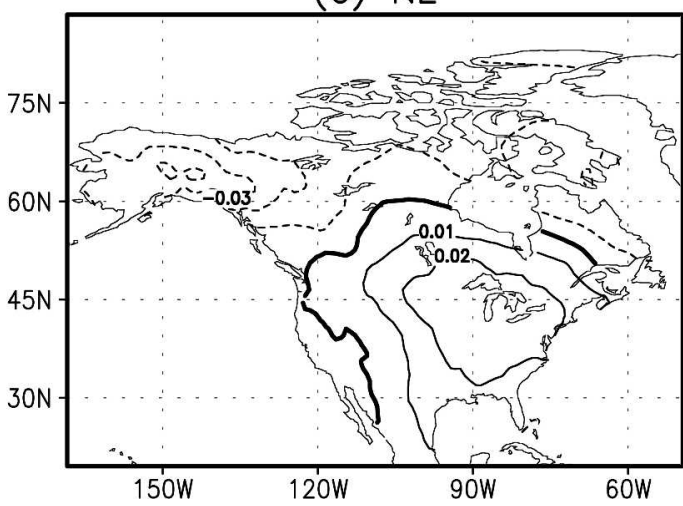

FIG. 6. (a) The leading PC of the SAT anomalies from the linear and nonlinear response to the ENSO SST index as extracted by the NN projection, shown by the solid line and dashed line, respectively. (b), (c) The corresponding PCA spatial patterns for linear and nonlinear components, respectively. The contour interval is 0.01 , and the spatial modes have been normalized to unit norm.

Alaska and northern Canada, strongly resembling the SAT anomaly patterns found in Figs. $5 \mathrm{c}$ and $5 \mathrm{f}$. The $\mathrm{PC}_{1}$ of the linear response is synchronous with the ENSO SST index, while the $\mathrm{PC}_{1}$ of the nonlinear response (the dashed line in Fig. 6a) has positive values not only during the El Niño winters (1958, 1966, 1973, 1983, 1992, and 1998), but also during La Niña winters (1950, 1956, 1971, 1974, 1976, 1989, and 1999, with the years labeled by the January of the ENSO winter). Hence, regardless of warm or cold episodes, the SAT has the same response pattern as depicted by Fig. 6c, which strengthens the negative SAT anomalies over Alaska and northwestern Canada during cold episodes and strengthens the positive SAT anomalies over the Canadian Plains and the Great Lakes region during warm episodes, thereby producing the asymmetric spatial patterns of the North American SAT anomalies during strong El Niño and strong La Niña (Figs. 5a and $5 d)$.

The scatterplots between the $\mathrm{PC}_{1}$ of the nonlinear response and the SST index form a parabola-like curve (shown by the solid circles in Fig. 7), which is well fitted by the polynomial function $\mathrm{PC}_{\mathrm{NL}}=-8.793-3.683 x+$ $9.318 x^{2}-0.051 x^{3}-0.102 x^{4}+0.003 x^{5}$, where $x$ is the
ENSO SST index. From the magnitude of the polynomial coefficients, the nonlinear response of the North American SAT to ENSO is clearly dominated by a quadratic response. For comparison, the scatterplot of the linear response is well fitted by the straight line $\mathrm{PC}_{\text {lin }}=$ $26.964 x$.

\section{c. A polynomial fit}

Now we consider a simple polynomial fit of the SST index to the SAT anomaly at each grid point. Let $x$ be the SST index and $x_{n}=x^{n}$, then $T$, the original SAT anomaly at a grid point, was fitted by $T=a_{0}+a_{1} \hat{x}_{1}+$ $a_{2} \hat{x}_{2}+\cdots+a_{N} \hat{x}_{N}$, where $\hat{x}_{n}$ is $x_{n}$ normalized. For 400 bootstrap samples and for each spatial point of the SAT anomaly field, regression coefficients $a_{0}, \ldots, a_{N}$ were computed. After ensemble averaging over all bootstrap samples, $a_{n}$ provided the spatial pattern associated with the $n$th order response to the SST index. When tested over independent data (i.e., data not selected in a bootstrap sample), the smallest MSE (averaged over all bootstrap samples) was found when $N=2$, indicating overfitted results when $N>2$. Hence there is no evidence for a cubic or higher-order nonlinear response to 


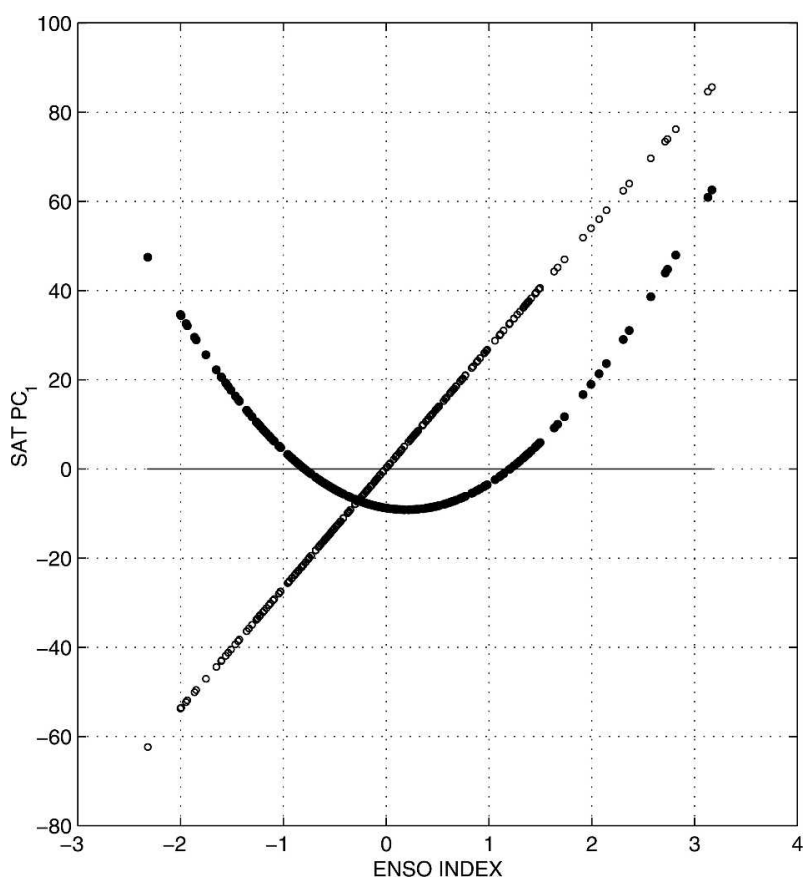

FIG. 7. Scatterplot between the ENSO SST index and the EOF $\mathrm{PC}_{1}$ of the nonlinear SAT response to ENSO, with the small solid circles revealing a curve. The linear SAT response is shown by the straight line of open circles.

ENSO. With $N=2$, the ensemble-averaged values of $a_{1}$ and $a_{2}$ are plotted in Fig. 8 .

The linear term (Fig. 8a) shows positive SAT anomalies over western Canada and Alaska and negative anomalies over the southeastern United States, resembling the pattern from the linear projection as shown in Fig. 6b. In contrast, the quadratic term (Fig. 8b) shows positive SAT anomalies over the United States and southern Canada and negative anomalies over Alaska and northern Canada, basically consistent with Fig. 6c, as well as Figs. $5 \mathrm{c}$ and $5 \mathrm{f}$, confirming that nonlinear response of North American winter SAT to ENSO is mainly a quadratic response.

\section{The nonlinear patterns of precipitation associated with ENSO}

\section{a. The NN projection results}

Similarly, the precipitation anomalies associated with the ENSO SSTA extracted by the NN projection is manifested by a curve in the 12-dimensional (12D) phase space of the precipitation $\mathrm{PCs}$, which when viewed in the $\mathrm{PC}_{1}-\mathrm{PC}_{2}-\mathrm{PC}_{3}$ subspace (Fig. 9), reveals appreciable nonlinearity in the precipitation response field to ENSO. When the SST index takes on its minimum value (i.e., strong La Niña), significant negative precipitation anomalies appear over the Pacific coast of Alaska and northwestern Canada and over both the southwest coast and the east coast of the United States, while positive anomalies appear from southern BC to northern California and south of the Great Lakes (Fig. 10a). When the SST index takes on its maximum value (i.e., strong El Niño), significant negative anomalies appear over the Pacific coast from northern BC to Alaska, and over the Great Lakes, while the United States south of $45^{\circ} \mathrm{N}$ (except to the south of the Great Lakes) and Mexico have positive anomalies (Fig. 10d). Comparing Figs. 10a and 10d, we see that the precipitation anomalies are basically antisymmetrical over centraleastern North America, while the anomaly patterns are in poor antisymmetry in the west (especially the coastal areas), suggesting that considerable nonlinearity occurs in the west coast. The precipitation anomalies associated with the half-minimum and half-maximum SST (a) linear

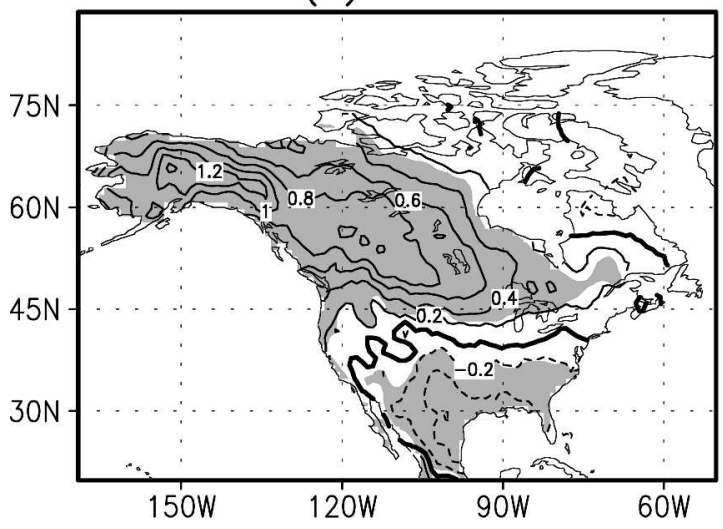

(b) quadratic

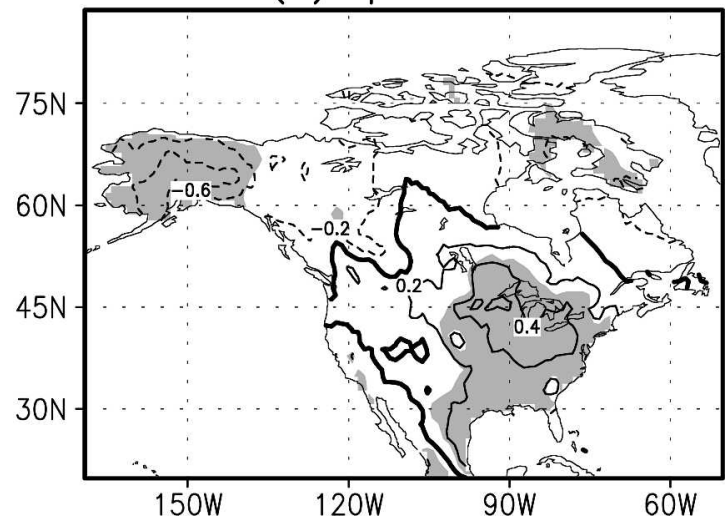

FIG. 8. The SAT anomaly patterns associated with the (a) linear and (b) quadratic terms of the ENSO SST index. The contour interval is $0.2^{\circ} \mathrm{C}$ and the shaded areas indicate statistical significance at the $5 \%$ level from bootstrapping. 


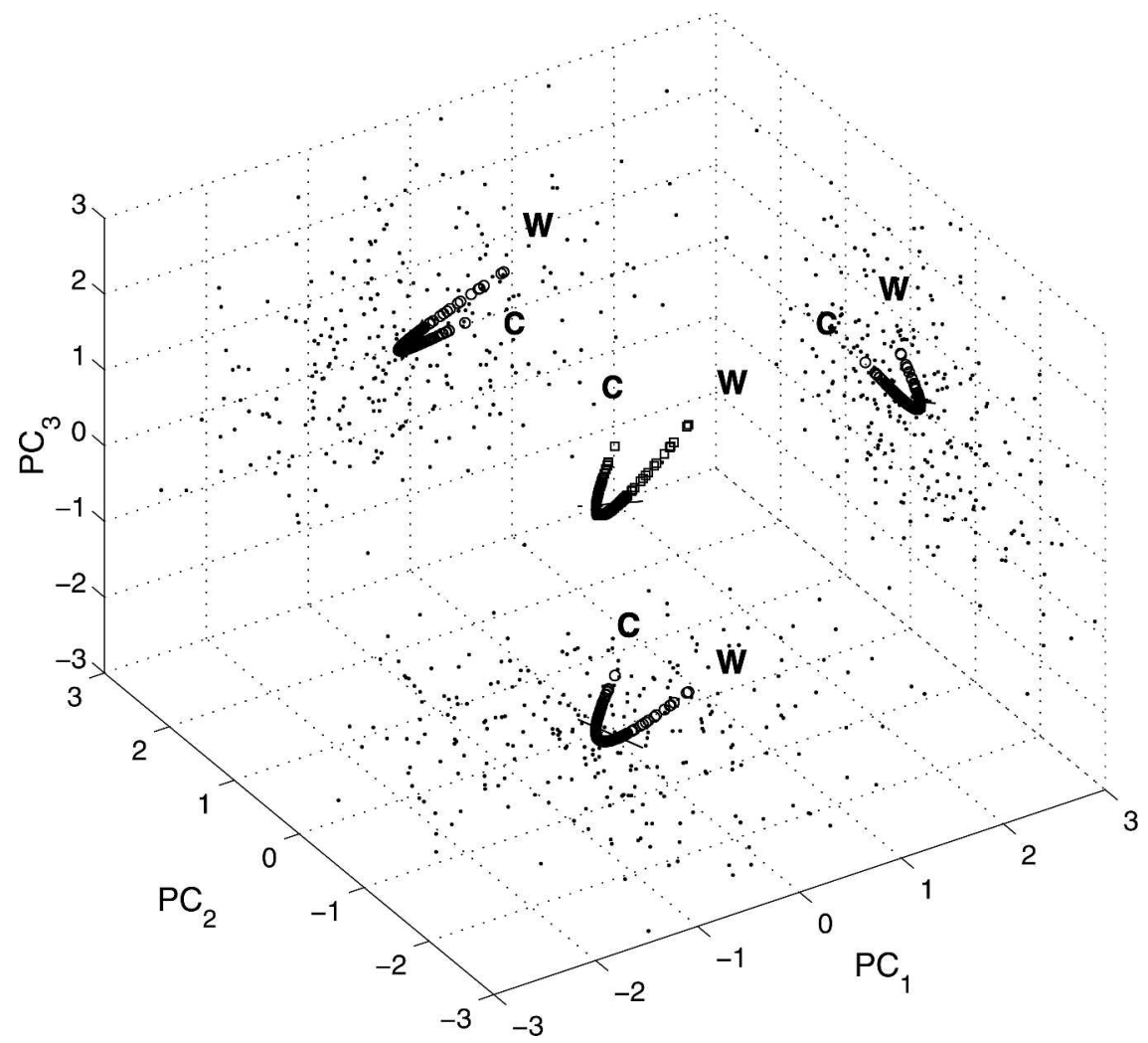

FIG. 9. As in Fig. 4, but for the precipitation anomalies.

index are shown Figs. 10b and 10e, respectively, with both the magnitudes of the anomalies and asymmetry (between the two panels) reduced.

The nonlinear response in the precipitation anomalies to the tropical SSTA is estimated by the difference between the precipitation anomalies in Fig. 10a and twice the anomalies in Fig. 10b (shown in Fig. 10c), and similarly the difference between the anomalies in Fig. $10 \mathrm{~d}$ and twice the anomalies in Fig. 10e (shown in Fig. 10f). Despite the large difference between Figs. 10a and $10 \mathrm{~d}$ and the smaller difference between Figs. 10b and $10 \mathrm{e}$, we see again that the precipitation anomalies in Figs. 10c and 10f agree well with each other, indicating that regardless of the sign of the SST index, the nonlinear response has significant negative precipitation anomalies over the Pacific coast of Alaska and northwestern Canada and positive anomalies over the west coast of United States and southern BC.

Again, the basic patterns in Fig. 10 are unchanged even if the two winters with the strongest ENSO warm episodes and the two winters with the strongest cold episodes were removed from the data record prior to the bootstrap computation.

Although in Fig. 10 the precipitation anomalies are largely confined over the coastal areas, this does not mean that the weak precipitation anomalies over interior areas can be ignored. A small change of precipitation inland (especially the areas with dry climate) can be important for regional agriculture and human activities. In Fig. 11, the normalized precipitation anomalies show significant anomalies stretching far inland. The nonlinear component of precipitation anomalies still appears mainly over the west but not focused on the coast anymore (Figs. 11c,f).

\section{$b$. The linear and nonlinear components of the precipitation response}

Similarly, by subtracting the linear projection (i.e., the linear response) from the NN projection, the nonlinear component of the precipitation response was obtained. This nonlinear component accounts for $26.9 \%$ of the variance in the $\mathrm{NN}$-projected precipitation anomaly data, while the linear component accounts for $73.1 \%$ of the variance. Then PCA was separately applied to the linear and nonlinear response fields of precipitation anomalies for the period 1950-2002, with the leading $\mathrm{PC}$ and the corresponding spatial pattern $\left(\mathrm{EOF}_{1}\right)$ shown in Fig. 12 (the PCA mode 1 explains over $99 \%$ of the variance for either response field).

When the $\mathrm{PC}_{1}$ of the linear response (the solid line in 
(a) $\min$

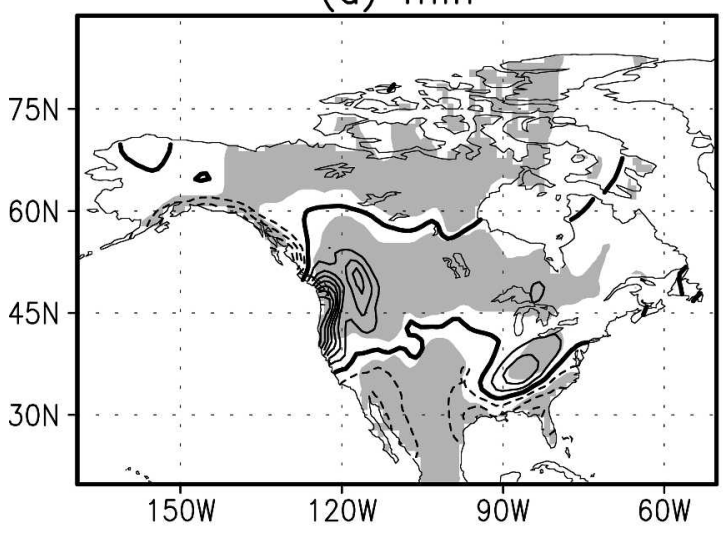

(b) $\min / 2$

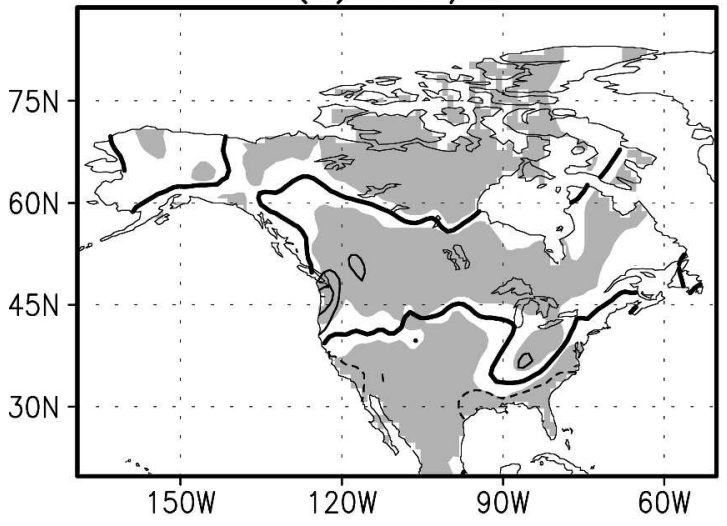

(c) $a-2 * b$

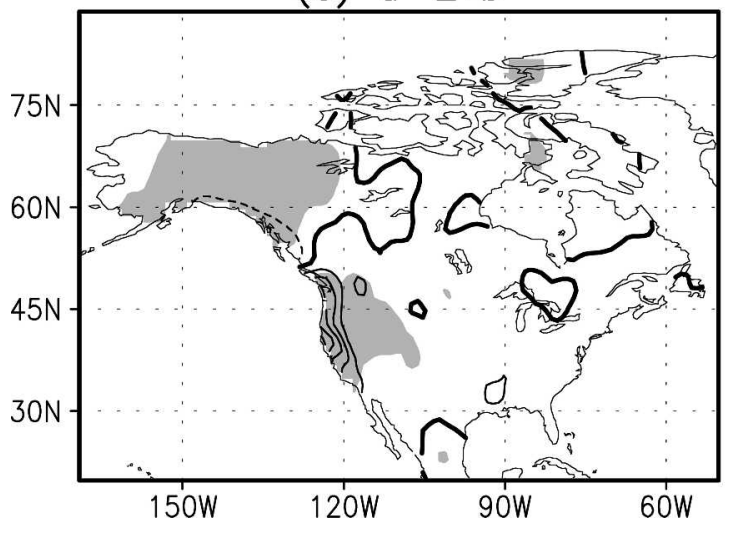

(d) $\max$

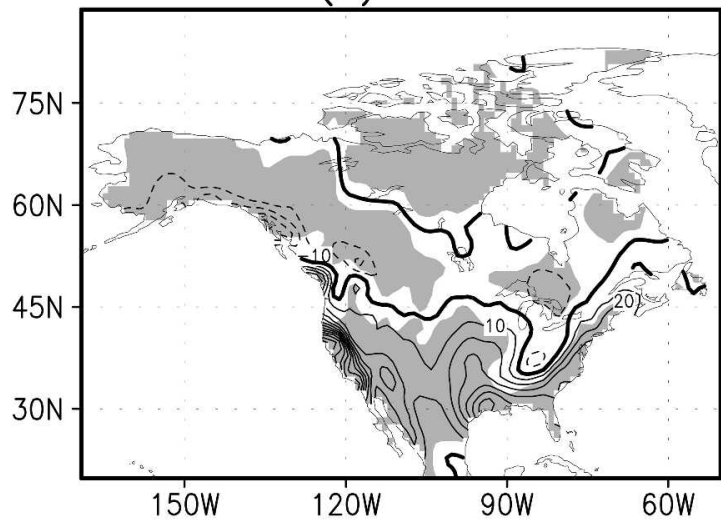

(e) $\max / 2$

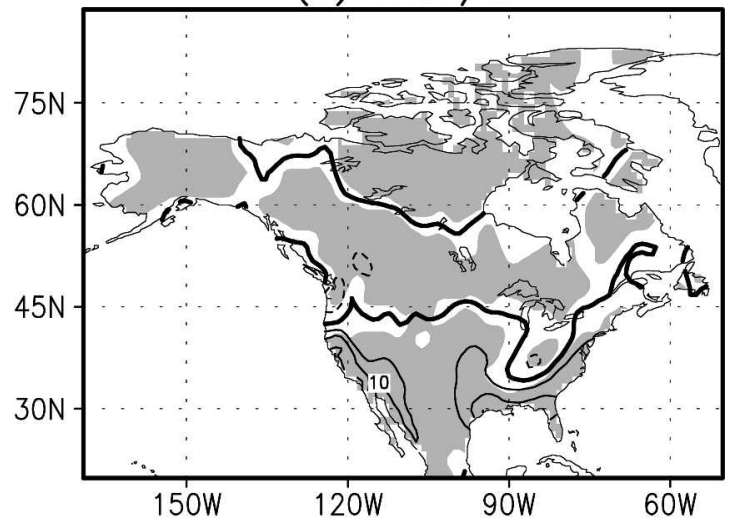

(f) $d-2 * e$

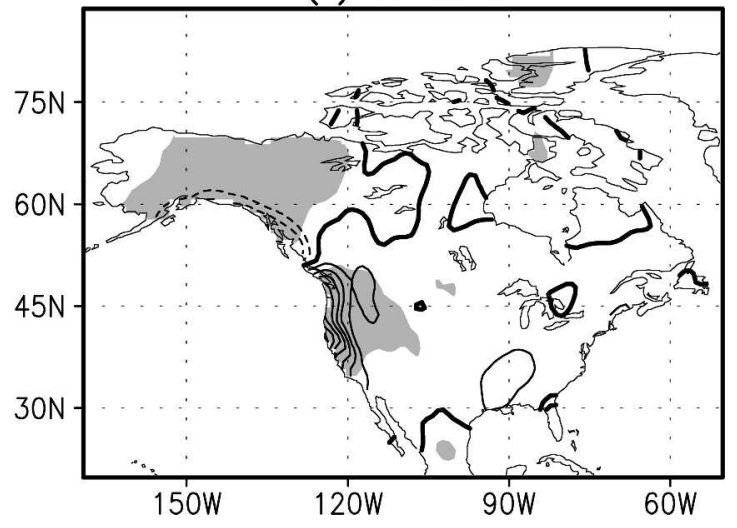

FIG. 10. As in Fig. 5, but for the precipitation anomalies; contour interval is $10 \mathrm{~mm}$.

Fig. 12a) takes on a positive value, the $\mathrm{EOF}_{1}$ of the linear response (Fig. 12b) shows a large positive precipitation anomaly area ranging from the east coast to the southwest coast of the United States and another weak positive area in northern Canada. A negative anomaly area over much of southern Canada and northern United States and another weak negative area over Alaska are also manifested by $\mathrm{EOF}_{1}$. Figure $12 \mathrm{~b}$ agrees well with Figs. 10b and 10e in pattern.
For the nonlinear response (Fig. 12c), its $\mathrm{EOF}_{1}$ shows positive anomalies over much of the United States and southern Canada, with the main center on the west coast at around $45^{\circ} \mathrm{N}$ and a weaker center along the southeast coast, and negative anomalies over northwestern Canada and Alaska, centering along the Pacific coast. Figure 12c agrees well with Figs. 10c and 10f. Normalizing the anomalies in Figs. 12b and 12c with the standard deviation yields anomaly patterns resembling 
(a) $\min$

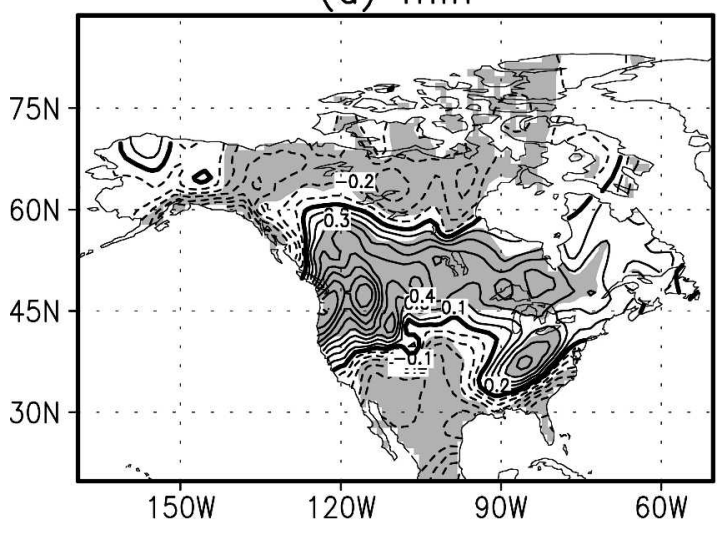

(b) $\min / 2$

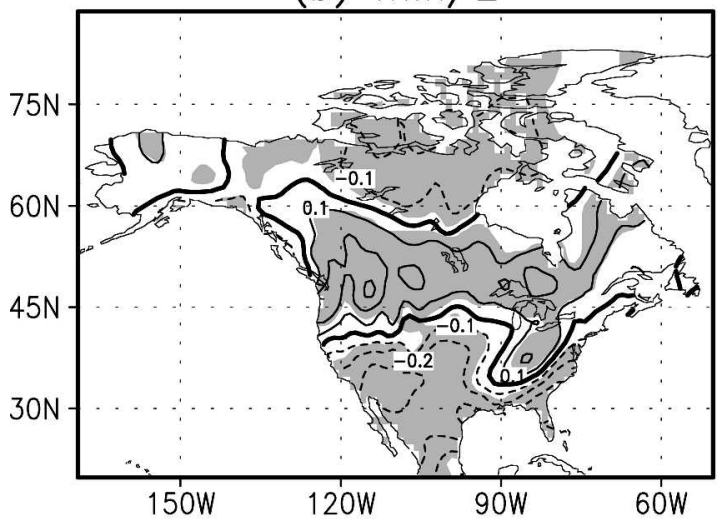

(c) $a-2 * b$

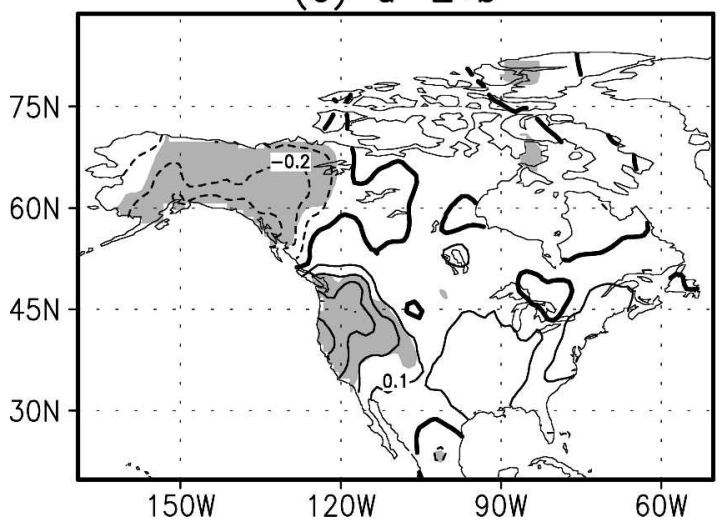

(d) $\max$

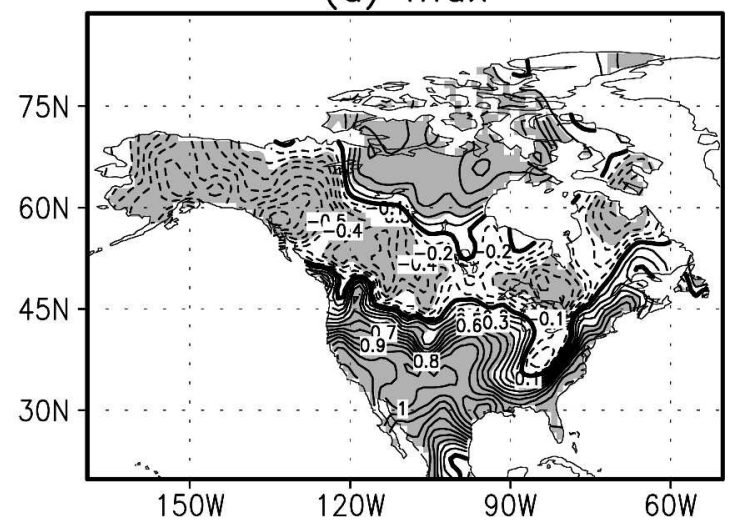

(e) $\max / 2$

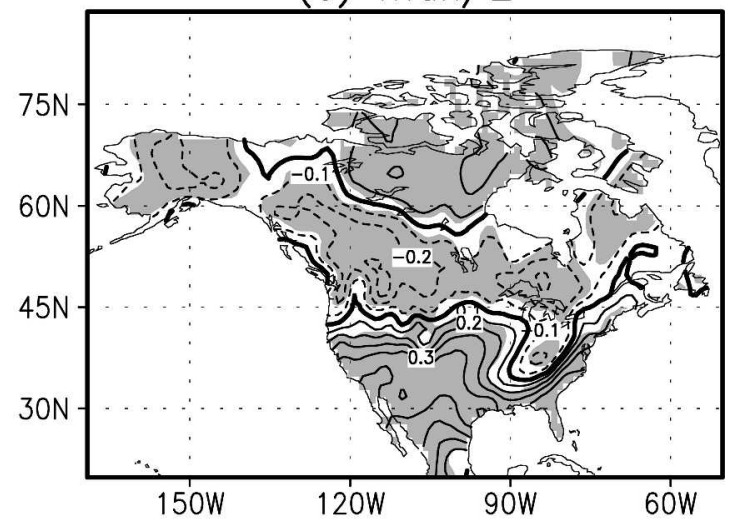

(f) $d-2 * e$

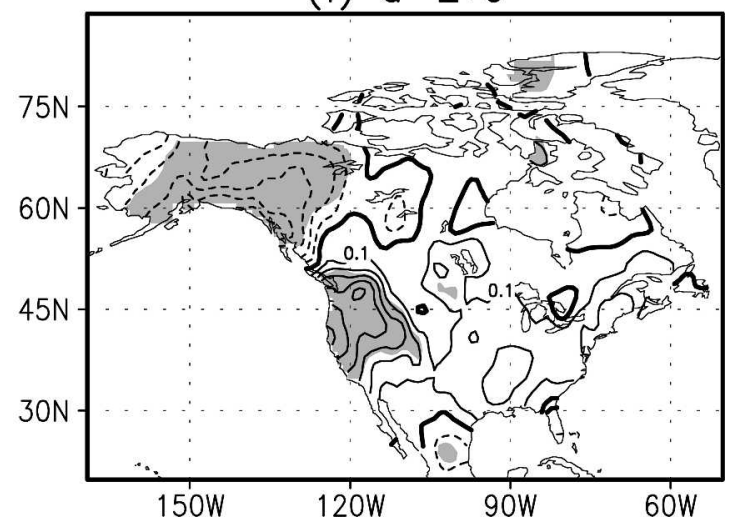

FIG. 11. As in Fig. 10, but for the normalized precipitation anomalies (obtained from dividing the actual precipitation anomalies shown in Fig. 10 by the corresponding standard deviation as shown in Fig. 1). Contour interval is 0.1.

Figs. 11e and 11c (or Fig. 11f), respectively. Since the $\mathrm{PC}_{1}$ of the nonlinear response has positive values not only during the El Niño winters, but also during La Niña winters (see the dashed curve in Fig. 12a), regardless of warm or cold episodes, the precipitation has the same response pattern as depicted by Fig. 12c, which contributes to the asymmetric precipitation anomaly patterns during extreme cold and warm episodes (Figs. $10 \mathrm{a}, \mathrm{d})$.

The scatterplots between the $\mathrm{PC}_{1}$ of the nonlinear response and the SST index gives a parabola-like curve (not shown), which can be fitted well by the polynomial function $\mathrm{PC}_{\mathrm{NL}}=-87.18-34.01 x+93.23 x^{2}-1.15 x^{3}-$ $1.18 x^{4}+0.01 x^{5}$, where $x$ is the ENSO SST index, indi- 
(a)

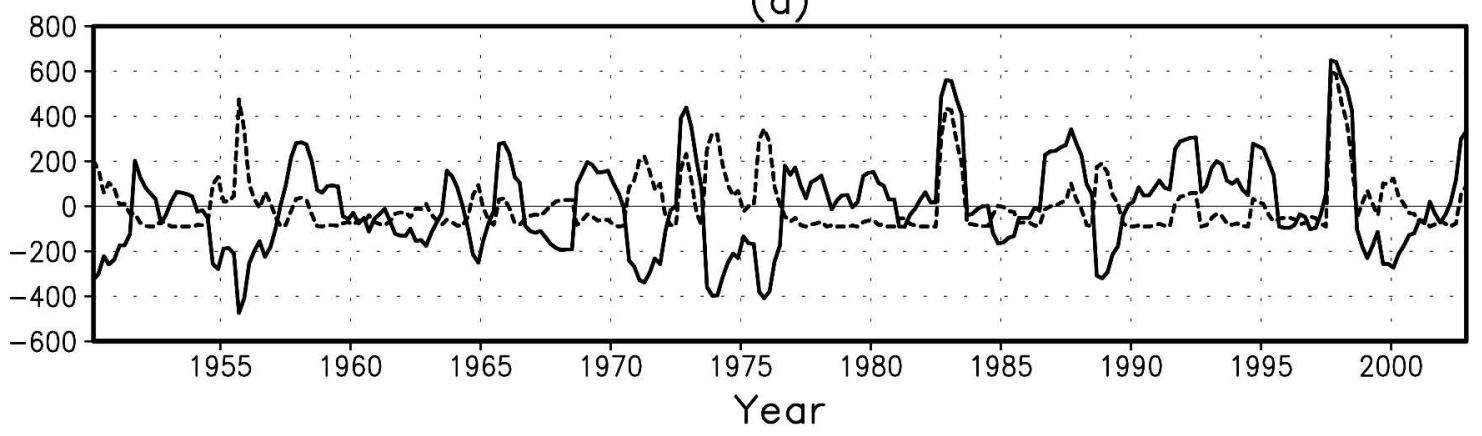

(b) Lin

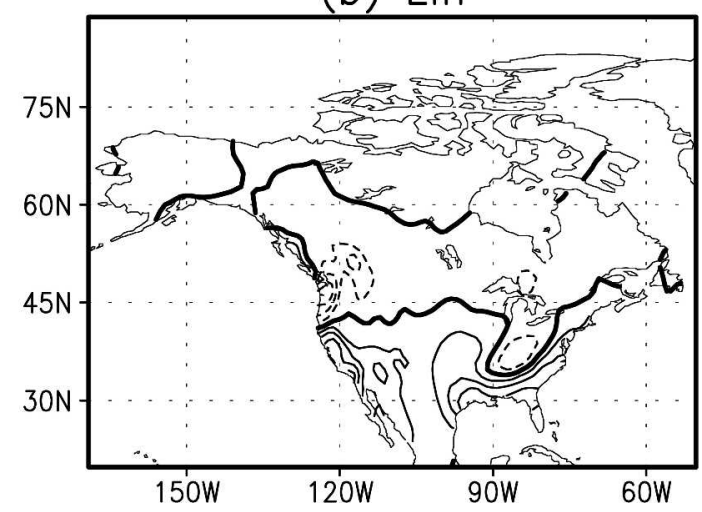

(c) $\mathrm{NL}$

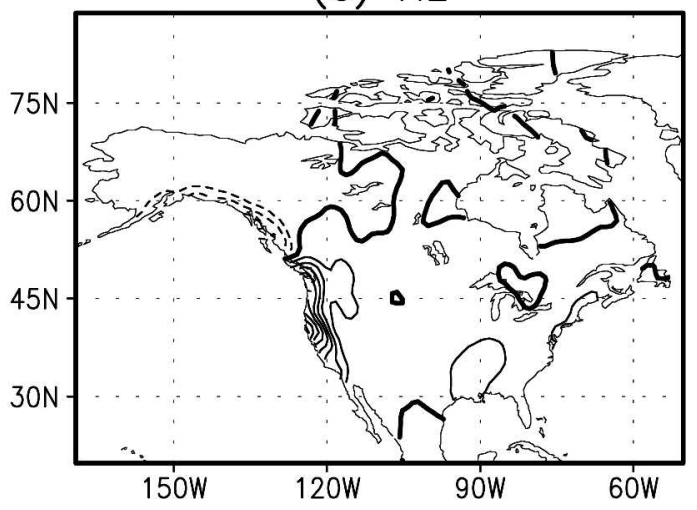

FIG. 12. As in Fig. 6, but for the precipitation anomalies. Contour interval in (b) and (c) is 0.01 .

cating that the nonlinear response of the North American precipitation to ENSO is also mainly a quadratic response.

\section{c. A polynomial fit}

Let the precipitation anomaly $(P)$ at each spatial point be fitted by $P=a_{0}+a_{1} \hat{x}_{1}+a_{2} \hat{x}_{2}$, where $\hat{x}_{1}$ and $\hat{x}_{2}$ are, respectively, $x$ and $x^{2}$ normalized ( $x$ being the
ENSO SST index). The ensemble-averaged values of $a_{1}$ and $a_{2}$ at all spatial points give the spatial patterns of the linear term and quadratic term, respectively (Figs. 13a,b). Using more higher-order terms in the polynomial fit leads to overfitting. The precipitation anomaly pattern shown in Fig. 13b agrees well with that in Fig. 12c, as well as Figs. 10c and 10f, confirming that nonlinear response of the North American winter precipitation to ENSO is mainly a quadratic response.
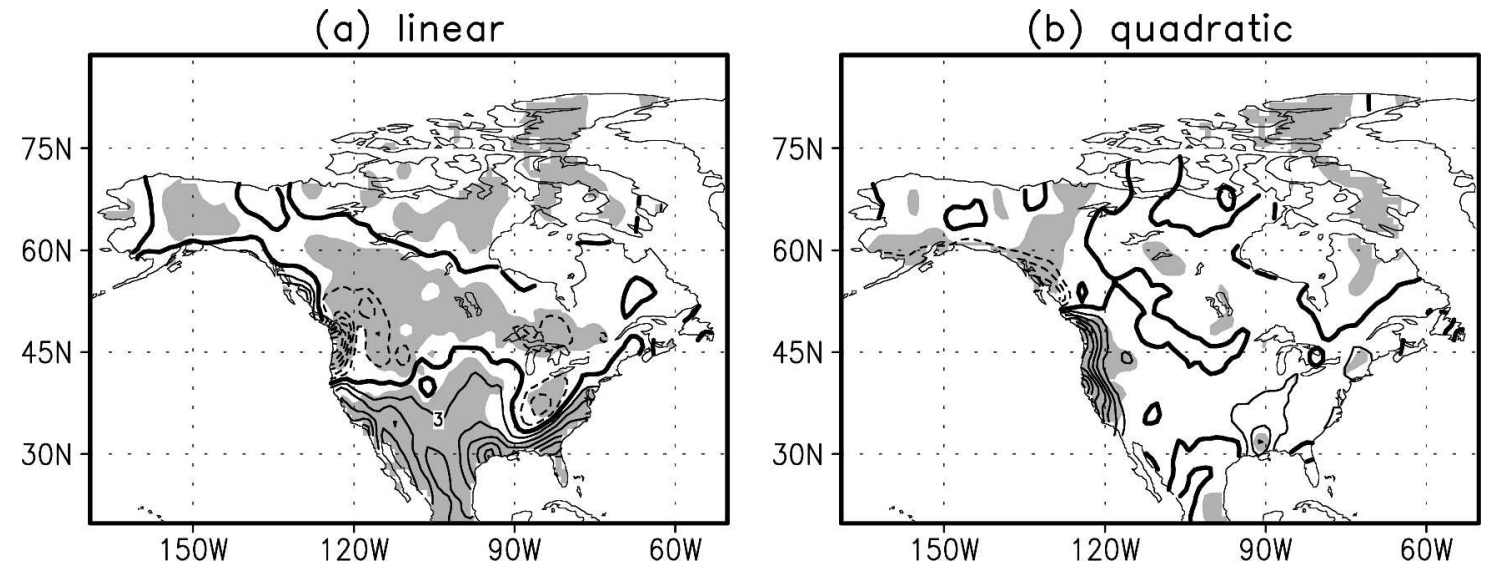

FIG. 13. As in Fig. 8, but for the precipitation anomalies; contour interval is $3 \mathrm{~mm}$. 

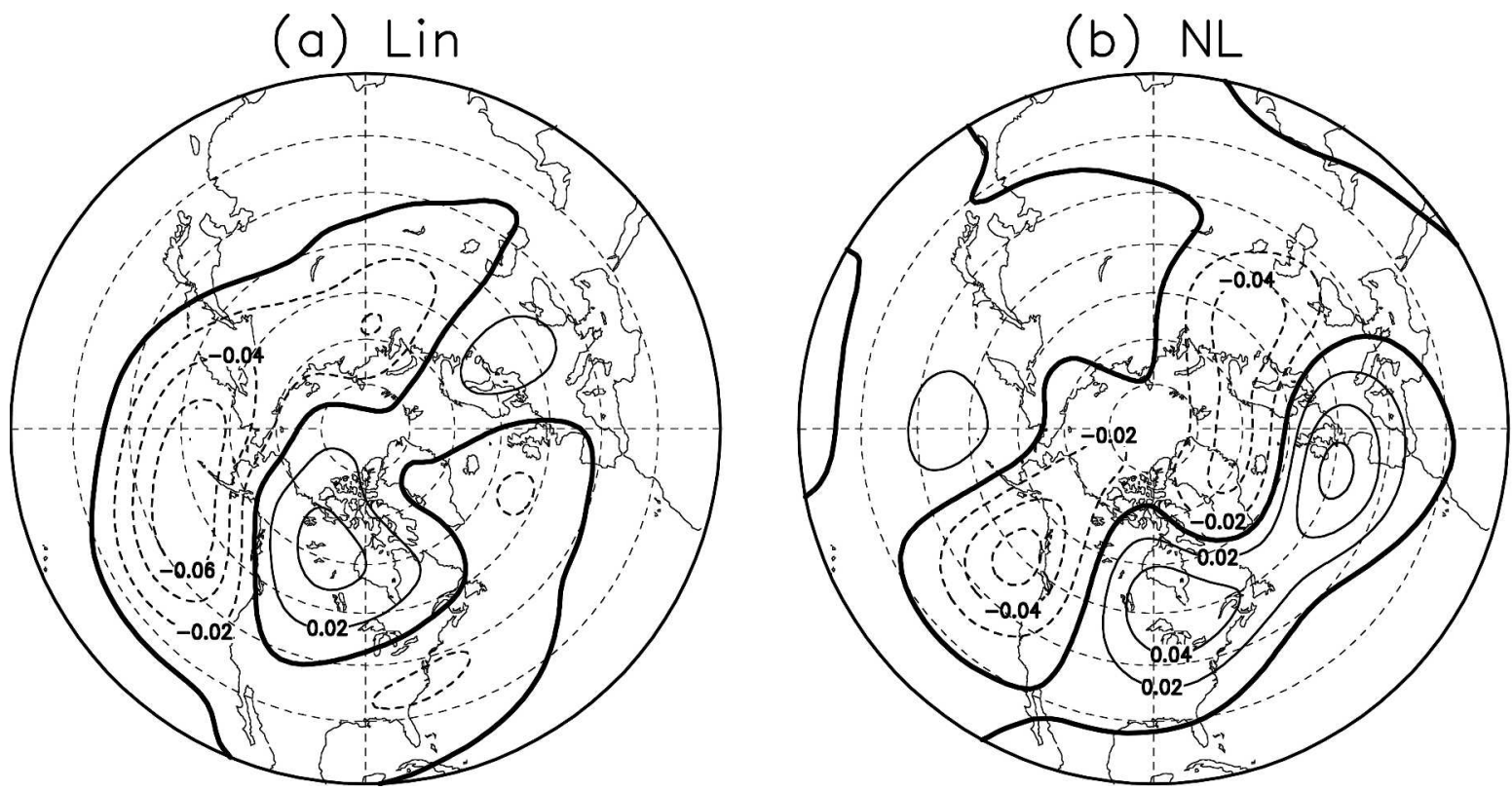

FIG. 14. Spatial patterns of (a) linear and (b) nonlinear response of the Northern Hemisphere winter $Z_{500}$ anomalies to the ENSO SSTA extracted by the NN projection. Pattern (a) is for El Niño; for La Niña, the sign of the anomalies is reversed. Pattern (b) is for both El Niño and La Niña. Contour interval is 0.02; the anomalies have been normalized to unit norm (reproduced from Wu and Hsieh 2004a).

\section{Relation to the upper circulation anomalies}

A similar nonlinear projection of the ENSO SST index onto the Northern Hemisphere winter $Z_{500}$ anomalies reveals linear and nonlinear response patterns as shown in Fig. 14. The linear response (Fig. 14a) shows a PNA-like pattern with strong negative anomalies over the North Pacific, positive anomalies over northwestern Canada, and weak negative anomalies over the southeastern United States. By geostrophy, over western Canada and Alaska, warmer air is transferred by anomalous southeasterlies leading to positive temperature anomalies, while over northeastern Canada colder air transferred by anomalous northerlies from the Arctic area results in the negative temperature anomalies, and over the southeastern United States the anomalous northeasterlies bring forth cooler than normal weather (Figs. 6b and 8a). The low pressure cell in the North Pacific (Fig. 14a) generates onshore flow of moist marine air along California to Mexico, leading to positive precipitation anomalies there (Fig. 13a). Meanwhile, the anomalous alongshore flow along the west coast (Fig. 14a) diverts the normal moist westerly flow farther north, thereby producing negative precipitation anomalies from Oregon to southern $\mathrm{BC}$ and positive precipitation anomalies farther north along the coast (Fig. 13a). The anomalous flow over the southern United States (Fig. 14a) is also consistent with the positive pre- cipitation anomalies there (Fig. 13a), while the anomalous high pressure over northern Canada is consistent with the negative precipitation anomalies there.

The nonlinear $Z_{500}$ response reveals positive anomalies over eastern Canada and the United States and negative anomalies over the Northeast Pacific Ocean and the west coast of Canada and the United States (Fig. 14b). The anomalous southerlies between the negative anomalies and positive anomalies transfer warmer air from lower latitudes, leading to positive temperature anomalies over the United States and southern Canada, while colder air is transferred from higher latitudes to Alaska and northeastern Canada, leading to negative temperature anomalies there (Fig. $8 b$ ). The anomalous low over the Pacific (Fig. 14b) brings moist air to the west coast from California to southern BC and dry Arctic air to Alaska, leading to the distribution of precipitation anomalies seen in Fig. $13 b$.

In brief, the temperature and precipitation anomalies associated with the ENSO SSTA can be well explained by the circulation anomalies extracted separately by the $\mathrm{NN}$ projection, confirming the robustness of the nonlinear (mainly quadratic) relation between the ENSO SSTA and North American winter climate. This quadratic relation is also found in an atmospheric general circulation model (AGCM) forced by tropical diabatic heating anomalies, where the relationship between the 
(a) $\operatorname{Lin}(\mathrm{SAT})$

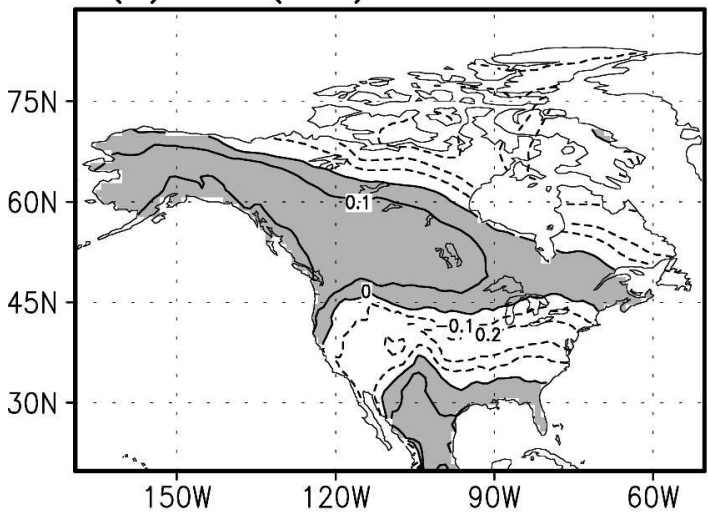

(b) Diff (SAT)

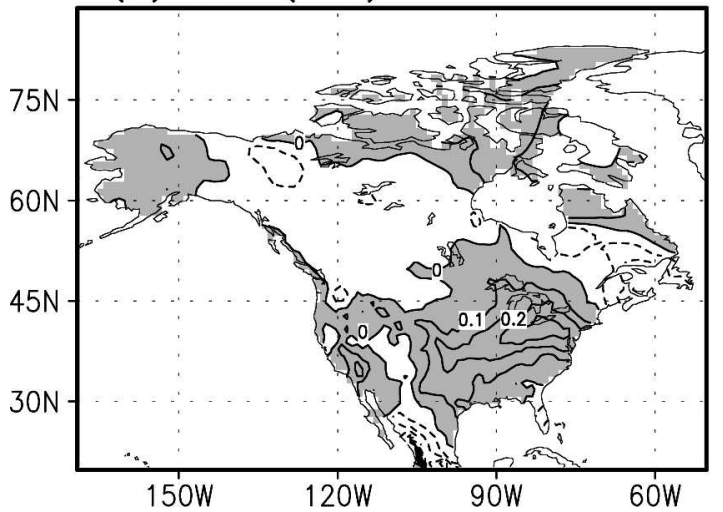

(c) $\operatorname{Lin}(\mathrm{RPCP})$

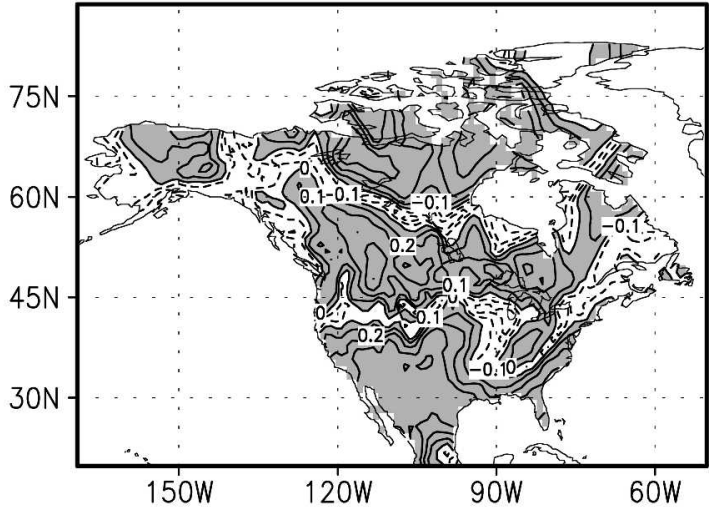

(d) Diff (PRCP)

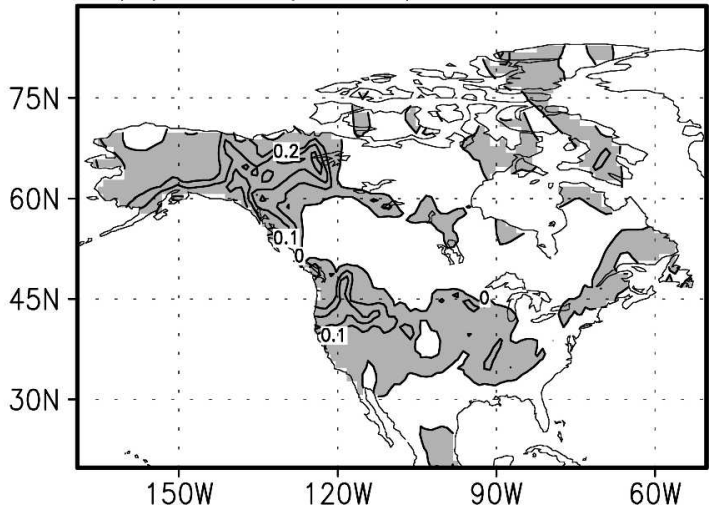

FIG. 15. Cross-validated correlation skills from the linear model for the (a) SAT and (c) precipitation, and the difference of skill between the nonlinear model and the linear model (nonlinear skill minus linear skill) for (b) the SAT forecast and (d) the precipitation forecast. Contour interval is 0.1 ; areas with positive values are shaded.

first PC of $Z_{500}$ anomalies (from an ensemble mean) and the amplitude of the forcing is linear, while the second PC of $Z_{500}$ anomalies has a nearly parabolic (quadratic) relationship with the amplitude of the forcing (Lin and Derome 2004), consistent with the results found in our work.

\section{Summary and discussion}

A fully nonlinear projection of the ENSO SST index onto the North American winter (November-March) SAT and precipitation anomalies has been achieved using neural networks, which reveals asymmetric atmospheric patterns associated with El Niño and La Niña. The NN projection consists of a linear response and a nonlinear response. For SAT, the linear response during El Niño has positive anomalies centered over Alaska and western Canada and weaker negative anomalies centered over the southeastern United States (Fig. 6b). In contrast, the nonlinear SAT response, which is excited during both strong El Niño and strong La Niña, has negative anomalies centered over Alaska and northwestern Canada and positive anomalies over much of the United States and southern Canada (Fig. 6c), centered around the Great Lakes.

For precipitation, the linear response during El Niño displays a positive anomaly area stretching from the east coast to the southwest coast of the United States and another positive area in northern Canada, in opposition to the negative anomaly area over much of southern Canada and northern United States and another negative area over Alaska (Fig. 12b). In contrast, the nonlinear precipitation response, which is excited during both strong El Niño and strong La Niña, displays positive anomalies over much of the United States and southern Canada, with the main center on the west coast at around $45^{\circ} \mathrm{N}$ and a weak center along the southeast coast and negative anomalies over northwestern Canada and Alaska (Fig. 12c). The normalized anomalies show more details of the nonlinear precipitation response to ENSO (Fig. 11). 
A polynomial fit of the SAT anomalies to the ENSO SST index, and a similar fit of the precipitation anomalies, confirm the nonlinear response of the SAT and precipitation to be mainly a quadratic response to ENSO.

There is an interesting contrast in the nonlinear SAT response and the nonlinear precipitation response, namely that the nonlinear response in precipitation is more focused on the western part of the continent, whereas the nonlinear response in the SAT is well manifested in the eastern half. The nonlinear response accounts for about one-fourth and one-third as much variance as the linear response for the SAT and precipitation, respectively. In some areas, the nonlinear response can surpass the linear response and can potentially enhance forecast skills (see the appendix). Both the linear and nonlinear response of SAT and precipitation to ENSO can be respectively explained by the linear and nonlinear response of the atmospheric circulation (as seen in the $Z_{500}$ anomalies) to ENSO.

Even with the extra skills contributed by the higherorder (quadratic) term of the ENSO SST index (Figs. $15 \mathrm{~b}, \mathrm{~d})$, the cross-validated forecast skills from the univariate nonlinear model are generally lower than those from multivariate linear models. For instance, using five leading PCs of the tropical Pacific SST anomalies as predictors, a linear CCA model shows higher skills than a univariate nonlinear model (using the leading SST PC and its quadratic term as predictors) for both SAT and precipitation over most areas of North America (figures not shown). In fact, multivariate nonlinear regression (MNLR) and nonlinear CCA (NLCCA) models via an NN approach have been developed and applied to forecast the tropical Pacific SST anomalies (see http://www.ocgy.ubc.ca/projects/ clim.pred/). The development of multivariate nonlinear models for seasonal climate prediction over extratropical regions is our next step.

Acknowledgments. Dr. David Viner of the Climatic Research Unit at the University of East Anglia kindly provided the surface air temperature and precipitation data. This study was supported by research and strategic grants from the Natural Sciences and Engineering Research Council of Canada and a contribution from Environment Canada.

\section{APPENDIX}

\section{Cross-Validated Forecast Skills}

The merit of finding the quadratic response can be tested by comparing the cross-validated forecast skills for the SAT (or precipitation) with and without the quadratic term of the ENSO SSTA. Using the ENSO SST index $(x)$ as a single predictor, the SAT (or precipitation) anomaly at each spatial point reconstructed from the 8 leading PCA modes (or the 12 leading PCA modes for the precipitation) can be predicted with a linear model,

$$
y=a_{0}+a_{1} x,
$$

and a nonlinear model with the quadratic term,

$$
y=a_{0}+a_{1} x+a_{2} x^{2} .
$$

The 53-yr winter data were divided into five equal segments. Data from one segment were withheld as validation data, while data from the other four segments (the training data) were used to build the models. Thus, an independent forecast was made for the period of the validation data using the models based on the training data. This procedure was repeated until all five segments were predicted, and the correlation between the predicted SAT (or precipitation) anomaly and the corresponding observation could be calculated over the whole record, yielding the a cross-validated skill at this point. The skills from the linear model for the SAT and precipitation are shown in Figs. 15a and 15c, respectively, and the difference of skill between the nonlinear model and linear model is shown Figs. $15 \mathrm{~b}$ and $15 \mathrm{~d}$ for the SAT and precipitation, respectively. It is not surprising to see that positive skills from the linear model (shaded areas in Figs. 15a,c) are basically consistent with the linear response pattern (Fig. $6 \mathrm{~b}$ for the SAT; Fig. $12 \mathrm{~b}$ for the precipitation). The major improvement brought by the quadratic term for the SAT forecast is mainly over the eastern United States and northeastern Canada (Fig. 15b) and for the precipitation forecast, over the west coast, northwestern Canada, and Alaska (Fig. 15d). The improvement of forecast skill (shaded areas in Figs. 15b,d) is also consistent with the nonlinear response patterns found by the nonlinear projection (Fig. 6c for the SAT; Fig. 12c for the precipitation), indicating that using the quadratic response can potentially improve the North American climate forecast.

\section{REFERENCES}

Barnston, A. G., 1994: Linear statistical short-term climate predictive skill in the Northern Hemisphere. J. Climate, 7, 15131564.

Derome, J., and Coauthors, 2001: Seasonal predictions based on two dynamical models. Atmos.-Ocean, 39, 485-501.

Efron, B., and R. J. Tibshirani, 1993: An Introduction to the Bootstrap. CRC, $456 \mathrm{pp}$

Hoerling, M. P., A. Kumar, and M. Zhong, 1997: El Niño, La Niña, and the nonlinearity of their teleconnections. J. Climate, 10, 1769-1786. 
,-- and T. Xu, 2001: Robustness of the nonlinear climate response to ENSO's extreme phases. J. Climate, 14, 12771293.

Horel, J. D., and J. M. Wallace, 1981: Planetary-scale atmospheric phenomena associated with the Southern Oscillation. Mon. Wea. Rev., 109, 813-829.

Hoskins, B., and D. Karoly, 1981: The steady linear response of a spherical atmosphere to thermal and orographic forcing. $J$. Atmos. Sci., 38, 1179-1196.

Hsieh, W. W., 2001: Nonlinear canonical correlation analysis of the tropical Pacific climate variability using a neural network approach. J. Climate, 14, 2528-2539.

_ 2 2004: Nonlinear multivariate and time series analysis by neural network method. Rev. Geophys., 42, RG1003, doi:10.1029/2002RG000112.

__ , and B. Tang, 1998: Applying neural network models to prediction and data analysis in meteorology and oceanography. Bull. Amer. Meteor. Soc., 79, 1855-1870.

Lin, H., and J. Derome, 2004: Nonlinearity of the extratropical response to tropical forcing. J. Climate, 17, 2597-2608.

Livezey, R. E., A. Leetmaa, M. Mautani, H. Rui, M. Ji, and A. Kumar, 1997: Teleconnective response of the Pacific-North American region atmosphere to large central equatorial $\mathrm{Pa}$ cific SST anomalies. J. Climate, 10, 1787-1820.

Montroy, D. L., M. B. Richman, and P. J. Lamb, 1998: Observed nonlinearities of monthly teleconnections between tropical Pacific sea surface temperature anomalies and central and eastern North American precipitation. J. Climate, 11, 18121835 .
Shabbar, A., and A. G. Barnston, 1996: Skill of seasonal forecasts in Canada using canonical correlation analysis. Mon. Wea. Rev., 124, 2370-2385.

- and M. Khandekar, 1996: The impact of El Niño-Southern Oscillation on the temperature field over Canada. Atmos.Ocean, 34, 401-416.

_, B. Bonsal, and M. Khandekar, 1997: Canadian precipitation patterns associated with the Southern Oscillation. J. Climate, 10, 3016-3027.

Smith, T. M., and R. W. Reynolds, 2004: Improved extended reconstruction of SST (1854-1997). J. Climate, 17, 2466-2477.

Trenberth, K. E., G. W. Branstator, D. Karoly, A. Kumar, N.-C. Lau, and C. Ropelewski, 1998: Progress during TOGA in understanding and modeling global teleconnections associated with tropical sea surface temperatures. J. Geophys. Res., 103, 14 291-14 324.

Wallace, J. M., and D. Gutzler, 1981: Teleconnection in the geopotential height field during the Northern Hemisphere winter. Mon. Wea. Rev., 109, 784-812.

Wu, A., and W. W. Hsieh, 2004a: The nonlinear Northern Hemisphere winter atmospheric response to ENSO. Geophys. Res. Lett., 31, L02203, doi:10.1029/2003GL018885.

— , and _ 2004b: The nonlinear association between ENSO and the Euro-Atlantic winter sea level pressure. Climate Dyn., 23, 859-868.

Zwiers, F., 1987: A potential predictability study conducted with an atmospheric general circulation model. Mon. Wea. Rev., 115, 2957-2974. 